\title{
EL FACTOR MILITAR EN ASIA CENTRAL
}

\author{
Ángel Gómez de Ágreda ${ }^{1}$ \\ Ministerio de Defensa
}

\begin{abstract}
Resumen:
La importancia geoestratégica de la región de Asia Central, en el corazón mismo del continente, se une a su relevancia como suministrador y como paso obligado de significativos recursos energéticos hacia algunas de las economías emergentes más importantes del siglo XXI. Las Fuerzas Armadas de las repúblicas que la componen tienen, no obstante, una importancia muy relativa en el contexto general de la región. Sus ejércitos, en su mayor parte, obsoletos y heredados de la etapa soviética, están más enfocados hacia el interior que hacia el exterior. Las 80la Organización del Tratado de Seguridad Colectiva y la Organización para la Cooperación de Shanghái, son el principal asidero internacional de una región dependiente de sus poderosos vecinos.
\end{abstract}

Palabras clave: Asia Central, energía, Fuerzas Armadas, OCS, OTSC.

Title in English: "The Military Factor in Central Asia”.

\begin{abstract}
:
The geostrategic importance of Central Asia, as it is located in the very heart of the continent, adds to its relevance as a provider and a route for significant energy resources which feed some of the most important emergent economies of the XXIst Century. The Armed Forces of the republics - the so called "stans" - deserve little consideration in the general context of the region. Their Armies, for the most part obsolete and inherited from the Soviets, are more focused on internal than external matters. The International Organizations in which they take part - be it the Community of Independent States, the Collective Security Treaty Organization or the Shanghai Cooperation Organization - are the most meaningful link in a region which is mostly dependent on its powerful neighbours.
\end{abstract}

Keywords: Central Asia, Energy, Army Forces, SCO, CSTO.

Copyright C UNISCI, 2012.

Las opiniones expresadas en estos artículos son propias de sus autores, y no reflejan necesariamente la opinión de UNISCI. The views expressed in these articles are those of the authors, and do not necessarily reflect the views of UNISCI.

\footnotetext{
${ }^{1}$ Ángel Gómez de Ágreda es Teniente Coronel del Ejército del Aire. http://dx.doi.org/10.5209/rev_UNIS.2012.n28.3840]
} 


\section{Factores geoestratégicos y geopolíticos}

Hay regiones llamadas a ser escenario de continuas disputas y conquistas; regiones cuyas características las convierten en paso obligado para todas las campañas de conquista, para todas las rutas del comercio, para todas las peregrinaciones. Muchas veces, estas regiones terminan por ser poco más que eso, lugares de tránsito, de paso, cuyos habitantes terminan por asimilar parte de lo bueno y de lo malo que discurre por ellas. En unos casos son las características geográficas propias o del entorno las que configuran el contorno de estos parajes, en otros, es la existencia más o menos permanente de grandes potencias o de grandes intereses en sus inmediaciones lo que les convierte en marcas, en zonas colchón donde convergen y chocan las líneas de expansión de sus vecinos.

La Península Ibérica, los Balcanes o Palestina son ejemplos clásicos de este tipo de regiones donde las culturas, las etnias y las religiones se mezclan con el paso de los pueblos por estos cuellos de botella geoestratégicos. No importa cuál sea la realidad política de la región, si está unida o dispersa, si es un Estado poderoso o una miríada de pequeños reinos o tribus; su posición geográfica acaba por convertirle en polo de atracción para los demás. Sean los otros pueblos vecinos o lejanos, busquen la seguridad en una huida de un enemigo o mejorar sus condiciones de vida, las rutas de sus invasiones, peregrinajes o migraciones terminan por atravesar estos territorios.

A la importancia geoestratégica de determinadas regiones hay que sumar la trascendencia geopolítica que puedan tener en función de su posición relativa a las grandes potencias. Un sencillo ejercicio sobre un mapa nos revela su ubicación. Basta con unir entre sí con líneas rectas a las grandes potencias y las potencias regionales para enmarcar la posición de las regiones en las que confluyen los intereses de todas ellas.

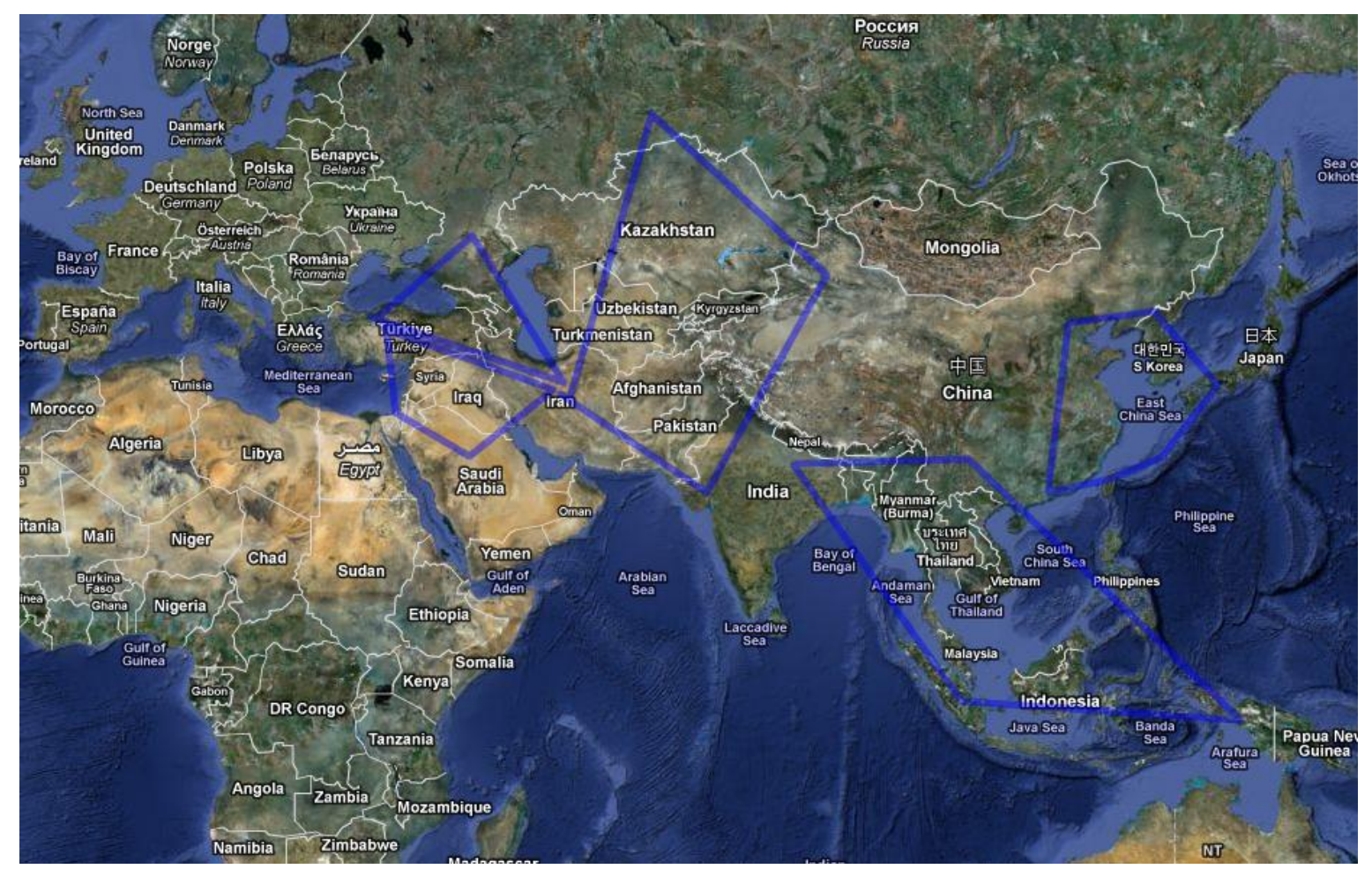

Mapa 1. La confluencia de intereses de las potencias. Elaboración propia sobre Google Maps. 
Siendo cierto que la mayor parte de las potencias tienen una permanencia prolongada en el tiempo, las regiones en las que convergen sus intereses son igualmente estables. La intersección de los intereses de una Turquía con vocación de liderazgo, de un Irán portando la bandera del chiismo, de Arabia Saudí como contraparte suní y de Israel, única potencia nuclear y mayor potencia militar de la región, nos define una región que incluye a un Iraq que no termina de encontrar la estabilidad y una Siria que vive en su interior la influencia de los cuatro vértices del polígono. No es casualidad que la inestabilidad surja en estas zonas en cuanto cesa la influencia apaciguadora de los intereses de potencias globales.

Igual razonamiento podríamos hacer en el caso de la convergencia entre la Federación Rusa, la propia Turquía y, de nuevo, Irán. La región caucásica se encuentra atrapada entre los tres imperios tradicionales: ruso, otomano y persa $\mathrm{y}$, sabiendo todos que es una zona fronteriza, pretenden hacer sentir su influencia en ella en mayor medida que sus rivales.

Más al este nos encontramos el singular caso del Mar del Sur de China, donde habría que incluir la influencia que la Flota norteamericana tiene en la región como uno de los vértices a tener en cuenta. Caso similar sería el del Mar de la China Oriental, que atrapa dentro de su área a la Península de Corea sin que se pueda decir que ésta es paso obligado para llegar a ninguna parte, es decir, sin que se den los condicionantes geoestratégicos en este caso. La geopolítica puede definir por sí misma el papel de los pueblos y las naciones sin el concurso de la geografía; al menos si descontamos la influencia que ésta ejerce en la misma génesis de las potencias y en su sostenimiento en el tiempo.

Quizás el más clásico de los escenarios que vienen marcados por la geopolítica y apoyados por la geoestrategia sea, sin embargo, el de Asia Central. El Gran Juego, como se conoce a la pugna por la influencia en la región entre los imperios ruso y británico desde los primeros años del siglo XIX hasta el comienzo de la Primera Guerra Mundial, es el ejemplo más documentado de la convergencia de intereses sobre una región que pocos han tenido el deseo de dominar, pero menos aún de permitir que fuera posible su dominio por parte de una potencia rival. La máxima extensión del Imperio Otomano y su control de esta región y las influencias que perviven del mismo en cuanto a su cultura y religión terminan por configurar el marco en que encuadraremos el escenario a estudiar.

La peculiaridad principal de lo que conocemos como Asia Central es su carácter absolutamente continental alejado de toda salida a mares abiertos. Kirguistán es el país más alejado del océano en todo el planeta y ninguno de los estados que la componen tiene siquiera próxima una salida al $\mathrm{mar}^{2}$. La región es el candidato ideal para formar parte de uno o varios estados de los que sí gozan de ese privilegio; la cuestión es determinar cuál de las grandes potencias que los rodean debería ser ese estado. Esa es la incógnita que han intentado despejar un imperio tras otro a lo largo de los siglos. En este contexto, los ejércitos de las tribus o países de Asia Central apenas si han podido suponer un relativo freno a las invasiones que llegaban de los cuatro puntos cardinales. Las Fuerzas Armadas actuales, herederas de aquellos

\footnotetext{
2 El Mar Caspio no termina de tener un estatuto jurídico definido. Sus aguas salobres no evitan que sea considerado por algunos como el lago más grande del mundo. La distinción no es banal ya que afecta al tratamiento que recibe a la luz del Derecho Internacional y, por lo tanto, al reparto de las riquezas energéticas e ictícolas y al tránsito por sus aguas. Si bien el sistema del Caspio es endorreico, es decir, que sus aguas no tienen salida más allá de la evaporación que sufran, existe un canal de comunicación a través del Don y el Volga hacia el Mar Negro y otros proyectos que permitirían el tránsito de buques de moderado tonelaje hacia aguas abiertas. La importancia del Caspio en muchos aspectos puede convertirlo, para bien o para mal, en un factor relevante en la estabilidad futura de la región al albergar en él muchos factores de cohesión y disgregadores a la vez.
} 
ejércitos, no juegan un papel mucho más significativo en la política exterior de las actuales repúblicas de Asia Central.

Las fuerzas militares y de seguridad de casi todos estos países son, en muchos casos, restos de serie que dejaron atrás los soviéticos hace ahora veinte años; en algunos, apenas un instrumento que mira más hacia el interior que hacia las fronteras exteriores. Los retos que Asia Central afronta en el siglo XXI son, no obstante, de una naturaleza tal que sus Fuerzas Armadas deberán adaptarse a misiones muy distintas a aquellas para las que fueron dotadas, desplegadas y organizadas en un principio. Igual que en el resto del mundo, la revolución en los asuntos militares ${ }^{3}$ deberá llegar a la región para mejor amoldarse a los riesgos y amenazas que les acechan.

Plenamente conscientes de sus capacidades y del papel que están llamados a jugar, la práctica totalidad de los países de la región han buscado integrarse en alianzas o asociaciones que incluyen a una o varias de las grandes potencias regionales y han pretendido explotar las oportunidades que su ubicación física ofrece para obtener beneficios de los intereses de las potencias globales en la zona. La necesidad de buscar apoyos y de diversificar mercados se ven muchas veces condicionadas por las infraestructuras existentes y por lazos históricos y culturales tanto o más que por barreras físicas. El cambio de foco de la política exterior estadounidense hacia Asia y las operaciones militares en dicho continente de la última década han influido también en la visibilidad y el interés de unos y otros por potenciar un acercamiento a la región con independencia de los intereses geoestratégicos que tuvieran por sí mismas.

Dos alianzas destacan sobre las demás desde el punto de vista de la seguridad. La Organización del Tratado de Seguridad Colectiva (OTSC) es una institución con un carácter básicamente de Defensa - y, consecuentemente, como se verá, de industria de Defensa mientras que la Organización para la Cooperación de Shanghái (OCS) se centra más en los asuntos de Seguridad, de convivencia y, potencialmente, comerciales. Dominadas respectiva y oficiosamente por la Federación Rusa y por la República Popular China, son organizaciones con unas características muy claramente definidas por la potencia dominante en cada caso. En las dos, como corresponde a la idiosincrasia de los pueblos orientales, los ritmos, los plazos y los símbolos son particularmente importantes. En ambos casos, además, la organización final surge como desarrollo o filial de otra anterior.

Con unas raíces más o menos profundas en la Historia, los países de Asia Central son, en su forma moderna, muy recientes. Todos, sin excepción, nacieron ha hecho ahora veinte años, fruto inesperado - y en muchos casos involuntario - de la desintegración de la Unión Soviética. Moscú diseñó la región a su conveniencia y sin tener en cuenta la idiosincrasia de cada pueblo. Con la misma frivolidad y falta de perspectiva que los imperios británico o francés en su día, se trazaron fronteras y se establecieron infraestructuras con total desprecio por los intereses locales. Las industrias servían los intereses centrales definidos por el Kremlin y los recursos eran compartidos sin tasa ni gravamen alguno entre lo que hoy son naciones independientes. Buena parte de los conflictos presentes y futuros de la zona tienen y tendrán su causa última en este diseño.

\footnotetext{
3 La revolución de los asuntos militares (RMA, Revolution in Military Affairs) es una expresión acuñada en los últimos tiempos para definir los cambios a que están siendo sometidas las Fuerzas Armadas de todo el mundo en función de las nuevas posibilidades y nuevos requerimientos de seguridad. Puede ampliarse información en http://www.comw.org/rma/.
} 


\section{Qué es y qué representa Asia Central}

Se entiende por Asia Central al conjunto de repúblicas, situadas al este del Mar Caspio, desgajadas de la Unión Soviética tras su desmembración en diciembre de 1991. Los Estados resultantes - Kazajstán, Uzbekistán, Kirguistán, Turkmenistán y Tayikistán - adoptaron las fronteras asignadas por Moscú en su división en Repúblicas Autónomas a lo largo del tiempo en que ejerció su dominio sobre ellas. En muchos casos, los gobernadores soviéticos pasaron a ser los presidentes de las repúblicas escindidas y, en alguno, siguen siéndolo.

La definición, no obstante, de dónde empieza y dónde termina la región está sujeta a discusión. Por sus características morfológicas y por buena parte de su historia, el territorio que hoy ocupa Afganistán podría estar incluido dentro de la misma. En realidad, podríamos asimilar Asia Central como el espacio que ha ido cambiando de manos de forma más o menos periódica entre los invasores orientales (mongoles, por ejemplo), persas, turcos y rusos; como esa tierra de nadie que quedaba entre el Imperio del Centro chino, el imperio zarista, el británico hasta la línea Durand y el Otomano. De hecho, no es posible entender la historia de Afganistán, incluso la más reciente, sin comprender la de sus vecinos del norte. Sin embargo, una vez hecha la salvedad, limitaremos nuestro análisis a las cinco repúblicas escindidas de la Unión Soviética.

Se puede decir, por consiguiente, que tanto la forma de gobierno como las instituciones y las fronteras mismas de la región vienen definidas por la conveniencia de un ente supranacional, la Unión Soviética, en cuyo seno estaban destinadas a permanecer como parte integrante del mismo. A diferencia de muchos otros estados, los de Asia Central no se atienen a criterios étnicos, culturales o religiosos de forma estricta porque los límites entre ellos se establecieron como una referencia administrativa más que como la delimitación de dos pueblos diferentes.

A los movimientos de población que, de forma natural, se producen entre dos territorios cualesquiera habría que añadir el carácter intrínsecamente nómada de muchos de los habitantes que pueblan la región, en la que el pastoreo tiene una importancia significativa. La población así entreverada se mezcló además con elementos del resto de la Unión Soviética procedentes, en unos casos de la migración voluntaria de rusos étnicos, en otros de las sucesivas deportaciones masivas llevadas a cabo en la época de Stalin. Por si fuera poco, la cultura de origen turco común a muchas de estas regiones y a otras vecinas - como la conflictiva provincia china de Xinjiang - favorece el intercambio y la mezcolanza entre ellas.

Este último rasgo característico de la mayor parte de la población local puede suponer un potenciador de riesgos y amenazas en tanto que favorece la ósmosis en los conflictos de carácter secesionista de la vecina uigur del Este. A efectos prácticos, existe una importante componente identitaria común a ambos lados de la frontera. No en vano, la misma génesis de la Organización para la Cooperación de Shanghái (OCS), el grupo denominado "Los cinco de Shanghái", está en la vocación declarada de definir las fronteras entre los nuevos estados y de ellos entre sí y de éstos con sus vecinos mayores, Rusia y China ${ }^{4}$.

Difícil labor tenía por delante una organización que debía sancionar unos límites tan arbitrarios como la misma existencia de los estados que la componían. Uzbekistán y

\footnotetext{
${ }^{4}$ Todavía en enero de 2011 Tayikistán cedía mil kilómetros cuadrados de territorio en disputa a la República Popular China. La zona, en la cordillera de Pamir, representa, no obstante, sólo una pequeña fracción de la reivindicación inicial china. A pesar de todo, Pekín se dio por satisfecho con este acuerdo que pone fin a un contencioso centenario.
} 
Tayikistán, por ejemplo, habían formado parte, inicialmente y durante cinco años, de una única República Socialista Soviética autónoma hasta que Moscú decidió dividirlas en 1929.

Más factores disgregadores se hicieron aparentes tras la disolución de la Unión Soviética. La aparición de fronteras donde antes había límites administrativos dejó patente el desigual reparto de los recursos que se da entre los cinco estados. Tres de ellos son ricos en depósitos energéticos de hidrocarburos - Kazajstán, Uzbekistán y Turkmenistán - mientras los otros dos carecen casi por completo de ellos. Sin embargo, Kirguistán y Tayikistán disponen de un enorme potencial de recursos hídricos y un desnivel natural que multiplica su potencial utilización para la generación de energía.

Claro está que, el mismo recurso que estos dos países necesitan utilizar para compensar su falta de yacimientos petrolíferos y gasísticos, se considera vital aguas abajo para sostener una agricultura intensiva en su uso y que fue implantada en la región por un régimen soviético que no tenía que someterse a consideraciones internacionales. La exigencia de acceso al agua, basada en el uso que se hace de la misma río abajo, en una agricultura con uso intensivo de este recurso, no despierta ninguna simpatía en los estados montañosos que apenas si tienen superficie cultivable propia - y, por lo tanto, posibilidad de aprovechar su agua para la agricultura - al tiempo que carecen de las importantes reservas de hidrocarburos de los países más occidentales.

No se está hablando de hipotéticos casus belli que pudieran surgir en un futuro, más o menos lejano, en Asia Central sino de realidades que ya han provocado enfrentamientos entre los distintos países. Las voladuras de algunas de las escasas vías férreas que transitan por la región tienen su origen en la pretensión de retrasar el acopio de materiales de construcción para la erección de centrales hidráulicas que condicionarían los caudales disponibles en los vecinos riparios.

No son, por lo tanto, las formas de vida, las costumbres, lo que ha cambiado en Asia Central. En realidad es la aparición de fronteras estatales lo que ha modificado el paisaje y lo que condiciona el ejercicio de las actividades que venían desarrollándose sin mayor problema durante milenios. Esto es tanto más así cuanto que los límites que se han establecido a los estados no son capaces de contemplar la distribución geográfica de las distintas etnias y sensibilidades sociales. A falta de una unidad étnica, los gobiernos se han basado, como en otras partes del mundo, en una identidad nacional basada en la lengua autóctona - y, normalmente, en detrimento del ruso, hablado por la generalidad de la población - como elemento cohesionador.

El poder tradicional se dispersaba en los clanes y hordas que no conocían de barreras políticas y era la fuerza de cada uno de estos grupos lo que les aupaba por encima de los demás o los postergaba a una posición subordinada. La dominación soviética introdujo la idea de la centralidad del poder y la uniformidad del lenguaje. Su desaparición supuso la necesidad de recomponer los equilibrios de poder si los gobernantes en ejercicio querían evitar una nueva dispersión tribal y, por lo tanto, ver disminuido su dominio. En muchos casos, como queda dicho, se recurrió a potenciar la diferenciación nacional en función de los idiomas propios de cada una - de vuelta a Babel - y como forma de exaltar el orgullo nacionalista. En todos, el aparato de seguridad del Estado y la manipulación de las narrativas supuso un elemento clave de control.

Entrando en la tercera década de existencia de estos países, los ejércitos y las fuerzas de seguridad de Asia Central juegan un papel más importante en la vida política interna de los 
países - y, si acaso en sus relaciones entre ellos - que en su proyección internacional más allá de la región donde, por otro lado, no tienen vocación ni capacidad real de operar.

La penetración de Al Qaeda en la región de la mano de grupos como la Unión para la Yihad Islámica (IJU Islamic Jihad Union) y el Movimiento Islámico de Uzbekistán (IMU Islamic Movement of Uzbekistan) y la exportación del radicalismo afgano suponen un problema mucho mayor que las amenazas convencionales. Estos grupos operan indistintamente en cualquiera de las repúblicas y han operado también en Afganistán. Si bien, hasta el momento, ninguno de estos grupos ha supuesto una amenaza seria para los estados centroasiáticos, su proliferación puede sentirse como una amenaza por parte de rusos o chinos que podrían verse tentados a intervenir para evitarla ${ }^{5}$.

\section{Bajo la sombra de Rusia y China}

La región por la que discurrió durante siglos la Ruta de la Seda ha quedado compartimentada de forma artificial. Después de su pertenencia a un imperio en sus distintas formas políticas y de ver como Moscú traía y llevaba poblaciones enteras a su antojo, de la noche a la mañana surgieron aduanas y controles fronterizos donde antes sólo las montañas y los ríos habían supuesto una barrera a la movilidad. Y es que, por lo general, la región entera se había ido incorporando casi siempre a cada conquistador y sólo en raras ocasiones una parte había evolucionado de forma independiente del resto.

Por eso los ejércitos de la región tienen las características que heredaron de la Unión Soviética y no las que corresponden a sus necesidades o a su vocación. Cada cual conservó en todo o en parte lo que el Kremlin había colocado en su territorio por consideraciones que sólo eran válidas a la luz de los intereses estratégicos del conjunto de la Unión y que para nada responden a las necesidades o intereses de las repúblicas individualmente. En Asia Central las Fuerzas Armadas nacen con los estados y ya en sazón de madurez; sin embargo, su composición sólo tiene sentido cuando se estudia como un todo - ya que es como fueron diseñadas - y nunca en función de los restos que el azar ubicó en cada país. A pesar de todo, aquí se hará el ejercicio de contemplar a cada una por separado y en su contexto y evolución.

Varios de los países de la región apenas si disponen de entre un cinco y un diez por ciento de superficie cultivable y no mucho más terreno apto para el despliegue de grandes unidades o para el uso de carros de combate. Lo escarpado del terreno y las condiciones climáticas son lo que determina las características de un Ejército, pero deberían ser las amenazas y los intereses estratégicos lo que definiesen sus capacidades. Veremos cómo, en el caso de Asia Central, las amenazas exteriores están limitadas por intereses de potencias mucho más fuertes que estos países y cómo los intereses están, por el momento, limitados por los de estas mismas potencias y por el alcance de sus propias y restringidas economías.

Las elevaciones medias de estos países condicionan sobremanera la operación de las aeronaves, limitando su capacidad de carga o, incluso, su usabilidad cuando las temperaturas son elevadas. Sin embargo, la naturaleza del terreno - sea esta montañosa o desértica, ambas predominantes en la región - impone la utilización de los medios aéreos para dotar a sus fuerzas de una flexibilidad de la que no podrían gozar de otro modo. Los ejércitos

\footnotetext{
5 Brill Olcott, Martha : “The 'Stans' at 20", Real Instituto Elcano- Observatorio de Asia Central, Working
} Paper (Diciembre 2011). 
centroasiáticos se caracterizan por disponer de una aviación de transporte mínima y, casi exclusivamente, dotada de helicópteros, lo que denota el escaso alcance y capacidad de proyección que se pretende conseguir con estos medios. De nuevo, las capacidades de una Fuerzas Armadas delatan las intenciones políticas de un Estado.

La condición continental de casi todos los estados, o su única salida al Mar Caspio, elimina o limita tremendamente su necesidad y capacidad para utilizar una Marina y hacer sentir su presencia en puertos lejanos. A pesar de todo, la magnitud e importancia relativa de los recursos marinos para los dos países con acceso a ellos justifican sobradamente la dedicación de recursos a la vigilancia y control de sus aguas. Sean éstos navales o aéreos, los medios empleados tienen que ser de suficiente entidad como para mostrar compromiso con la misión acometida, al tiempo que ser lo suficientemente modestos para adaptarse a lo limitado de su radio de acción potencial. La creciente importancia de la región litoral caspia para los estados ribereños está haciendo que la inversión en buques de guerra sea muy significativa en el global de las adquisiciones militares regionales.

Asia Central es, por lo tanto, un territorio abierto que se ha visto, de repente, surcado por unas líneas fronterizas que le son fundamentalmente ajenas. Es una región de paso, de tránsito para caravanas o para rebaños; una región dura y difícil para los asentamientos fijos. Sus ejércitos, heredados en su diseño y filosofía de necesidades que les son ajenas, deberán evolucionar para hacer frente a los verdaderos retos que tiene la zona. Como es natural, esta evolución dependerá del ritmo a que pueda o quiera ir el nivel político que sigue - también él - absolutamente condicionado por su pasado soviético. Los recursos disponibles también condicionarán el modo en que se produce la adaptación de los medios a los fines. Aquí, el muy distinto nivel de renta disponible entre los distintos estados puede dar lugar a desequilibrios importantes que den paso a conflictos interestatales.

Como queda dicho, otro factor de enorme importancia en la configuración de las Fuerzas Armadas de estos países - incluso de los países mismos - es su posición periférica respecto de la Federación Rusa y de la República Popular de China. Encajonados entre países con fuertes - y, a menudo, contrapuestos - intereses y con unos ejércitos tremendamente superiores, su situación es similar a la de Suiza en el continente europeo. Así, de constituir una ruta de paso, han acabado por ser un reducto montañoso que proporciona una cierta tranquilidad a sus grandes vecinos.

Aparte de la influencia y limitaciones que impone dicha proximidad, no hay que olvidar la percepción de estas dos grandes potencias de que Asia Central puede ser una puerta de entrada para el radicalismo islamista y para el narcotráfico procedente de las plantaciones de Afganistán. En el caso del terrorismo, la experiencia rusa en el Cáucaso hace que sean particularmente susceptibles a la posibilidad de infiltración de ideologías religiosas extremistas desde el sur. En cuanto a China, la identidad étnica y religiosa más o menos común con los habitantes oriundos de la provincia de Xinjiang y la aversión a cualquier inestabilidad de Pekín, convierte esta amenaza en una prioridad de su política exterior.

El caso del narcotráfico no es menos significativo para las dos potencias asiáticas. China ya experimentó en su sociedad y en su gobierno los efectos del opio en una de las guerras más sucias jamás libradas y que sigue presente en la memoria colectiva del pueblo chino. Para la declinante demografía rusa, la tasa de cien mil muertos anuales debidos al consumo de heroína, es un precio que difícilmente puede permitirse. Para ambos países es una prioridad la contención del avance de ambos fenómenos y para las cinco repúblicas centroasiáticas independientemente del beneficio que puedan extraer por sí mismas de su erradicación o 
mitigación - supone una oportunidad de representar un papel clave en la seguridad de sus vecinos y, por lo tanto, convertirse en aliados inapreciables de éstos.

\section{Tratados y Organizaciones}

Todo lo dicho se enmarca, además, en los objetivos de las alianzas y asociaciones que mantienen con rusos y chinos. Para estos países, la contribución militar de las repúblicas centroasiáticas a sus propias Fuerzas Armadas, si bien bienvenida desde el punto de vista político, resulta poco trascendente desde el militar, y puede llegar a ser una carga por la necesidad adicional de coordinación y de incremento de la huella logística que supone ${ }^{6}$. Sin embargo, unos ejércitos orientados a impermeabilizar ese vientre blando que supone la región para chinos y rusos, supondría un valor añadido importante para ambos.

\begin{tabular}{|l|l|l|l|l|}
\hline & Uzbekistán & Tayikistán & Kazajstán & Kirguistán \\
\hline OSCE & $\mathrm{X}$ & $\mathrm{X}$ & $\mathrm{X}$ & $\mathrm{X}$ \\
\hline Bosnia & & $\mathrm{X}$ & & $\mathrm{X}$ \\
\hline Kosovo & $\mathrm{X}$ & & & \\
\hline Conf. Minsk & & & $\mathrm{X}$ & \\
\hline UNMIL & & & & $\mathrm{X}$ \\
\hline UNMIS & & & & $\mathrm{X}$ \\
\hline
\end{tabular}

Participación de las naciones de Asia Central en misiones internacionales. Fuente: Elaboración propia a partir de The Military Balance

\begin{tabular}{|l|l|l|l|l|l|l|}
\hline & & Kazajstán & Uzbekistán & Kirguistán & Turkmenistán & Tayikistán \\
\hline \multirow{3}{*}{$\begin{array}{l}\text { Gasto en } \\
\text { Defensa (1) }\end{array}$} & 2007 & 1.164 & - & 44 & 99 & 78 \\
\cline { 2 - 7 } & 2008 & 1.608 & - & 47 & 84 & 80 \\
\cline { 2 - 7 } & 2009 & 1.353 & - & 44 & - & 49 \\
\hline $\begin{array}{l}\text { Gasto en } \\
\text { Defensa per } \\
\text { cápita (2) }\end{array}$ & 2007 & 76 & - & 8 & 21 & 11 \\
\cline { 2 - 7 } & 2008 & 105 & - & 9 & 17 & 11 \\
\hline & 2009 & 85 & - & 8 & - & 7 \\
\hline del PIB & 2007 & 1,12 & - & 1,17 & 0,81 & 2,13 \\
\hline
\end{tabular}

\footnotetext{
${ }^{6}$ Aunque sólo sea por la creciente obsolescencia de los sistemas de armas de las repúblicas centroasiáticas, ya que la interoperabilidad sigue estando garantizada al ser el material bélico de éstas, en su inmensa mayoría, de procedencia soviética.
} 


\begin{tabular}{|l|l|l|l|l|l|l|}
\hline en Defensa & 2008 & 1,18 & - & 0,92 & 0,71 & 1,74 \\
\cline { 2 - 7 } & 2009 & 1,25 & - & 0,8 & - & 0,97 \\
\cline { 1 - 5 } Efectivos(3) & & 49 & 67 & 11 & 22 & 9 \\
\cline { 3 - 7 } Paramilitares & 32 & 20 & 10 & 0 & 8 \\
\hline
\end{tabular}

(1) Millones de dólares USA

(2) Dólares USA

(3) Miles de personas. Tanto para "Efectivos", como para "Paramilitares"

Datos sobre Defensa de los países de Asia Central. Fuente: Elaboración propia a partir de The Military Balance

Es por esto último que, de las dos principales organizaciones que engloban a los estados centroasiáticos, la Organización del Tratado de Seguridad Colectiva, promovida por Moscú, puede tener una filosofía más clásica en cuanto a la cooperación en materia fundamentalmente de defensa, la Organización para la Cooperación de Shanghái, impulsada desde Pekín, se fundamenta, precisamente, en el combate contra los tres males que suponen el terrorismo, el separatismo y el radicalismo con un mayor énfasis en la seguridad y la cooperación que en los asuntos estrictamente militares.

\subsection{CEI}

La Comunidad de Estados Independientes (CEI) es una organización que nace con la disolución de la Unión Soviética; de hecho, su carta fundacional es el certificado de defunción de ésta ${ }^{7}$. El 8 de diciembre de 1991, los Presidentes de Bielorrusia, Ucrania y Rusia se reunieron para firmar el Acuerdo de Creación que, en realidad, era el de disolución de la Unión. El mismo documento fundacional de la CEI admite que sus miembros son estados independientes y certifica, de este modo, la desaparición del Estado soviético. El mismo nombre de la organización pretende enfatizar el hecho de que sus miembros han dejado de ser parte de una única entidad para convertirse en entes individuales. La importancia de hacer hincapié en esta circunstancia estriba en la necesidad de los socios de Rusia de reafirmar su identidad frente a Moscú en un momento en el que acababan de adquirir - más bien de recibir, en el caso de las repúblicas centroasiáticas, que nunca la buscaron - su nuevo estatuto como país. Es más, el acuerdo se firma en las afueras de la ciudad de Brest, en Bielorrusia, como contraste buscado a la centralización que presidía las relaciones en el seno de la Unión Soviética.

De acuerdo con su carta fundacional, los objetivos de la CEI son:

- Implementar de la cooperación en los ámbitos político, económico, ambiental, humanitario, cultural y otros,

- Fomentar el desarrollo económico y social integral y equilibrado de los Estados Miembro en el espacio económico común, la cooperación interestatal y la integración

\footnotetext{
7 Para más información se puede visitar la página web de la Comunidad de Estados Independientes, en http://ecis.info/index.php (en ruso).
} 
- Garantizar los derechos y libertades fundamentales de conformidad con los principios y normas generalmente reconocidos de Derecho Internacional y los documentos de la OSCE,

- Fomentar la cooperación entre los Estados Miembro para garantizar la paz y la seguridad internacionales, así como la puesta en práctica de medidas eficaces para reducir los armamentos y los gastos militares ${ }^{8}$, la eliminación de las armas nucleares y otras armas de destrucción masiva y alcanzar el desarme general y completo,

- Promocionar la libre circulación, contactos y movimientos de ciudadanos de los Estados Miembro en la Comunidad

- La asistencia judicial recíproca y la cooperación en otras esferas de las relaciones jurídicas

- Buscar soluciones pacíficas a las controversias y a los conflictos entre los estados de la Comunidad $^{9}$

Los firmantes dejaron claro desde el principio la disponibilidad de acoger en la nueva organización al resto de las repúblicas ex soviéticas y a aquellos otros estados que sintieran sus objetivos como propios. Este hecho puede resultar relevante más de dos décadas después visto el acercamiento de Teherán a la CEI y a la Organización para la Cooperación de Shanghái en un contexto de creciente aislamiento internacional de la República de Irán.

Sólo unos días después de la firma del Acuerdo por parte de estos tres primeros países, el resto de las repúblicas que conformaban la Unión, excepto Georgia y las tres bálticas, rubricaron el Protocolo de Alma-Ata por el cual se adhirieron a la Comunidad. Georgia terminó por asociarse en 1993, mientras que Estonia, Letonia y Lituania iniciaron una aproximación a Occidente y a la Alianza Atlántica que conllevó numerosas tensiones con Moscú $^{10}$. Sobre el papel, la mayor parte de la antigua Unión Soviética permanecía unida por vínculos en varios campos.

No obstante, ni Turkmenistán ni Ucrania llegaron nunca a ratificar el Acuerdo y, por lo tanto, a ser miembros de pleno derecho de la CEI. En el caso de la primera, la llamada Revolución Naranja y el conflicto que la enfrentó a Rusia a causa de los derechos de paso y precio del gas natural que atraviesa o llega a su territorio tuvieron mucho que ver con la decisión. Su acercamiento a la OTAN con vistas a una posible integración en la misma paralelos a los de Georgia, por otro lado - estuvieron siempre en la raíz del problema. Para Turkmenistán, la coherencia con el estatuto de país neutral que tiene reconocido por las Naciones Unidas le llevó a cambiar su estatus al de Miembro Asociado en agosto de 2005.

\footnotetext{
8 Sin embargo, uno de los efectos de esta alianza - igual que de otras - es el generar mercados básicamente cautivos de venta de armamento, normalmente desde la potencia dominante en la organización, en base a la necesidad de actuación combinada y la interoperabilidad de los sistemas de armas.

9 Veremos que el mecanismo no sirvió para evitar la confrontación de Rusia con Georgia, igual que la presencia oficiosa de Ucrania en las reuniones tampoco evitó el choque con Moscú en cuanto al tránsito del gas por su país y los precios que debía pagar por su suministro.

${ }_{10}$ Que culminaron en 2007 con los ataques informáticos de denegación de servicio distribuido contra Estonia y que llevaron a la solicitud, por parte de ésta, de activación del Artículo V del Tratado de Washington.
} 
Consejo de Jefes de Estado

Consejo de Jefes de Gobierno

Consejo de Ministros de Asuntos Exteriores

Consejo Económico

Consejo de Ministros de Defensa

Consejo de Comandantes de Tropas de Frontera

Asamblea Interparlamentaria

Tribunal Económico de la Mancomunidad

Órganos de la CEI. Fuente: Elaboración propia sobre datos de la web de la CEI.

La dependencia de las Repúblicas Autónomas de Moscú - y de sus vecinas en lo que se refiere a las relaciones comerciales y a los recursos energéticos, minerales y agroalimentarios - justifica de alguna manera la necesidad que sintieron, en un primer momento, la mayor parte de las nuevas naciones de mantener unos vínculos que, sin menoscabar su independencia, les permitían seguir haciendo uso de unos mecanismos por los cuales llevaban décadas rigiéndose.

Cuando en agosto de 2008 se produjo la confrontación entre Rusia y Georgia de la que resultó la escisión de Osetia del Sur y Abjasia, Georgia era todavía miembro de la CEI, aunque ya había anunciado que dejaba de participar en su estructura de defensa, el Consejo de Ministros de Defensa, desde febrero de 2006, con motivo de su candidatura a ingresar en la Alianza Atlántica. Ni las reuniones periódicas ni los mecanismos puestos en marcha por la CEI pudieron impedir la guerra ni las continuas injerencias de unos y otros en los asuntos caucásicos de ambos lados de la frontera (Chechenia, muy en particular, por parte georgiana). Lógicamente, recién terminado el enfrentamiento armado, Georgia solicitó su baja en la Comunidad; baja que se formalizó un año más tarde.

Ese mismo año de 2009, de resultas de la guerra y de la separación de Georgia, los representantes de Uzbekistán, Tayikistán y Turkmenistán decidieron no acudir a la reunión anual.

La aparición de nuevas iniciativas en unos casos, la actitud dominante de Moscú en otros y la creciente madurez de algunas repúblicas en otros más han hecho, desde entonces, que la CEI vaya perdiendo una parte de su protagonismo inicial. Indudablemente, en el ámbito de la seguridad y la defensa, el liderazgo lo han asumido la Organización el Tratado de Seguridad Colectiva y la Organización para la Cooperación de Shanghái. 


\subsection{OTSC}

La Organización del Tratado de Seguridad Colectiva (OTSC ó CSTO en sus siglas en inglés) ${ }^{11}$ se crea dentro del marco de la CEI y agrupa a cuatro de las cinco repúblicas centroasiáticas; Turkmenistán quedó fuera del Tratado de Taskent por el que se funda y también de la Organización, por decisión propia. Uzbekistán. referente por población, renta y Fuerzas Armadas en aquel momento en Asia Central, mantuvo inicialmente una actitud vacilante ante el Tratado y sólo se adhirió en 2008.

El Tratado de Seguridad Colectiva, embrión del que surgirá la OTSC, supone un intento de la Federación Rusa de dotar de una estructura militar a la CEI. Firmado en 1992 con vocación de sustituir al Pacto de Varsovia como contrapeso de la OTAN, su gestación estuvo marcada por el momento político de debilidad rusa y de reticencia por parte de algunos de sus antiguos socios en la URSS. Superado el periodo de inmadurez del Tratado, en 2002 se consolidó como Organización del Tratado de Seguridad Colectiva con diversas entradas y salidas de miembros respecto del grupo original.

Tanto el escudo como los estatutos de la OTSC recuerdan inevitablemente a sus equivalentes de la OTAN en un guiño que pretende hacer pensar en una relación similar entre sus componentes y en una capacidad del mismo orden de magnitud. Sin embargo, el peso específico relativo de la Federación Rusa respecto del resto de los aliados y la falta de vínculos entre estos la diferencian de una Alianza Atlántica (que, hasta no hace mucho, había podido mantener la ilusión de dos patas - americana y europea - comparables entre ellas aun manteniendo enfoques diferentes). La alianza euroasiática no ha gozado nunca de algo parecido a una paridad entre sus socios y ha estado siempre tutelada - cuando no directamente financiada y dirigida - desde Moscú.

Eso no quiere decir que se pueda considerar a la OTSC como una mera continuación de Rusia en el aspecto político, como quedó demostrado en el escaso entusiasmo que mostraron sus miembros ante el reconocimiento de Osetia del Sur y Abjasia por el Kremlin. A pesar de las presiones de Moscú, la mayor parte de los socios prefirieron no abrir la caja de Pandora de los reconocimientos de regiones que podría afectarles en un futuro.

En un movimiento significativo, el pasado día 20 de diciembre de 2011, la OTSC decidió que el establecimiento de destacamentos o instalaciones militares de terceras potencias en los países miembros debería contar con la aprobación consensuada de todos los socios. El acuerdo, claramente diseñado para restringir la presencia norteamericana en la región, pretende reforzar la pretensión rusa - pero también china - de romper el bloqueo a que se siente sometida por los establecimientos estadounidenses a su alrededor. Igualmente, la presencia rusa en la Base Aérea de Kant, en Kirguistán, es una estupenda cabeza de puente para un despliegue rápido en la zona en caso de necesidad.

La Organización llevó a cabo un ejercicio práctico contra el crimen internacional y el narcotráfico en Bielorrusia en 2005 y desarrolla ensayos periódicos en que participan las fuerzas de sus países miembro.

\footnotetext{
${ }^{11}$ Se puede encontrar más información en http://www.dkb.gov.ru/ (en ruso).
} 


\subsection{OCS}

La Organización para la Cooperación de Shanghái (OCS) ${ }^{12}$ representa un nuevo modelo de alianza muy distinto de los caducos ejemplos que sobreviven desde el siglo XX. Algunos han querido ver interesadamente en la OCS a otro contrapunto a la Alianza Atlántica, otro intento de la nueva Rusia de buscar alianzas para no quedarse aislada frente a su viejo rival occidental. Para los que así piensan, el mundo sigue siendo en blanco y negro, de derechas o izquierdas, de rojos y azules. La OCS, sin embargo, busca un equilibrio entre grandes potencias vecinas y una colaboración que no llega a ser una alianza, una entente cordiale que beneficie a todos; lo que los anglosajones llaman un win-win.

Nacida como "Los cinco de Shanghái”, surge de la necesidad de delimitar las fronteras entre las nuevas repúblicas centroasiáticas, la Federación Rusa y la República Popular China. La zona concentraba millones de tropas a ambos lados de unas fronteras que, por lo remoto de su ubicación para Moscú y Pekín y por la naturaleza misma del terreno por el que discurren, estaban particularmente mal definidas, y amenazaba con suponer un detonante para una confrontación que nadie quería. Al mismo tiempo, distraía recursos y atención de otros problemas mucho más contemporáneos y suponía un freno potencial a una colaboración entre rusos y chinos que tenía - y sigue teniendo - un enorme potencial.

En 1996, menos de un lustro después de la disolución de la Unión Soviética, la creación de la Organización suponía para Rusia la posibilidad de centrar sus esfuerzos militares en la amenaza que acechaba con la inestabilidad política y los movimientos insurgentes renacidos a ambos lados del Cáucaso. Permitía que sus medios diplomáticos se enfocasen en una frontera con la OTAN que cada día era más cercana, en Europa y en unos Balcanes, que seguían su proceso de fragmentación en contra de los intereses moscovitas. De forma simultánea, Moscú se libraba de la carga financiera que suponían las repúblicas centroasiáticas, deficitarias por lo general, aunque fuera solamente en un porcentaje de su aportación ${ }^{13}$.

Para China, en pleno inicio de la ebullición económica, significaba la posibilidad de cerrar sus flancos norte y oeste para poder centrarse en potenciar la costa pacífica y, desde ella, sus importaciones de materias primas y exportaciones de manufacturas. La materialización de esta posibilidad ha demostrado ser un movimiento de gran trascendencia. Hoy Pekín está siendo capaz de enfatizar su política naval precisamente gracias a este hecho. China, evidentemente, no teme una invasión o una agresión desde las repúblicas centroasiáticas. La Federación Rusa tampoco estaba en condiciones de suponer un problema militar ya que estaba en su momento de mayor debilidad. No obstante, las preocupaciones chinas - que terminarán por definir la línea estratégica de la Organización - son lo que llaman los tres males: el extremismo, el separatismo y el terrorismo.

Estas preocupaciones prácticamente calcaban la llamada "triada" de intereses rusos:

- Evitar los conflictos armados en la región y la consiguiente inestabilidad

- Vigilar las fronteras exteriores de las nuevas repúblicas para mitigar las amenazas que suponían el extremismo islamista y los tráficos ilícitos y

\footnotetext{
${ }^{12}$ Tampoco es objeto de este estudio pormenorizar en los aspectos históricos u organizativos de la Organización para la Cooperación de Shanghái, a pesar de su indudable relevancia para el tema tratado. Para más información, puede acudirse a la página web de la Organización para la Cooperación de Shanghái (OCS), en http://www.sectsco.org/EN/ (en inglés).

${ }_{13}$ Antes de la disolución de la Unión Soviética, Moscú subsidiaba a las repúblicas centroasiáticas con más de 25.000 dólares anuales, cantidad que se redujo a un tercio en 1992.
} 
- Mantener una presencia militar en la zona que le acreditase como gran potencia y le permitiese una actuación rápida y decisiva ${ }^{14}$.

La OCS se marcará como metas la erradicación de estos temores compartidos y la conquista de las pretensiones individuales de las grandes potencias al tiempo que se hará eco de las "necesidades" de los gobiernos de sus socios menores. Los regímenes de los "estanes" - como algunos dieron por llamar a las recién nacidas repúblicas por la desinencia común de sus nombres - se sostenían sobre las mismas figuras que habían regido sus destinos desde antes de su independencia. Para estos gobernantes, los extremismos, definidos por ellos mismos, suponían la mayor amenaza para la continuidad de sus puestos. El supuesto apoyo que iban a recibir de los dos grandes tutores de la región garantizaba su supervivencia. El tiempo se encargó de demostrar que, cuando llegó el caso en Kirguistán - ni la OTSC ni la OCS hicieron lo más mínimo para sostener al gobierno y sí para preservar los intereses rusos y chinos en el país. Sin embargo, cuando, en 2005, el gobierno uzbeco de Karimov provocó una matanza al dispersar una manifestación, la Organización se volcó en un apoyo unánime y contrario a las críticas occidentales.

El separatismo preocupaba mucho más en los dos socios mayores. Tanto Rusia como China tienen regiones "díscolas" con ciertas veleidades separatistas. Rusia, plenamente implicada en el levantamiento checheno, bien podía hacer uso del apoyo político que suponía el rechazo a los separatismos y a las insurgencias internas. Para China, las regiones de Xinjiang - que comparte frontera con algunos de los países de Asia Central, además de una religión y etnia común con varios de ellos - y de Tíbet suponían, y siguen suponiendo hasta cierto punto, un quebradero de cabeza por sus pretensiones secesionistas ${ }^{15}$.

El tercero de los males, el terrorismo, comenzaba a afectar a todos en mayor o menor medida. Demostrando una cierta anticipación, la OCS abordó ya entonces el problema de los grupos terroristas que llegaban exportados de Afganistán. El corazón de la Organización es su lucha contra los movimientos islamistas que, aunque ajenos a la región y al carácter moderado de la visión del Islam que se practica en su mayor parte en ella, comenzaban a expandirse con los movimientos étnicos de la frontera sur común con Afganistán.

La RATS (Regional Anti-Terrorist Structure - Estructura Regional Antiterrorista) fue la respuesta específica de la Organización a estos tres retos, aunque su nombre parece hacer especial énfasis en el del terrorismo. Se creó en junio de 2002, esto es un año después de que Los cinco de Shanghái dieron paso, con la incorporación de Uzbekistán, a la Organización para la Cooperación de Shanghái. Precisamente fue en la capital uzbeca, Taskent, donde se ubicó la sede de esta agencia permanente bajo de mando de un General.

Cabe preguntarse qué sentido tiene crear una agencia para hacer frente a las tres amenazas definidas como objetivo de una organización cuando ésta queda ya enmarcada en aquellas. La respuesta parece estar en la pretensión de dotar a la OCS de un alcance más

\footnotetext{
${ }^{14}$ Ruiz González, Francisco J.: "La Organización de Cooperación de Shanghái en su X aniversario”, Documento de análisis del Instituto Español de Estudios Estratégicos 018/2011, (Junio 2011), en http://www.ieee.es/Galerias/fichero/docs_analisis/2011/DIEEEA18_2011OrganizacionCooperacionShanghai.pdf

is China tiene, no lejos de la región, otro contencioso territorial compartido con Pakistán y con India en la zona de Cachemira-Jammu. También mantiene otra disputa en la región de Assam por la provincia de ArunachalPradesh. Ambas tienen unas implicaciones estratégicas mucho mayores que los diferendos mantenidos sobre delimitación territorial en Asia Central.
} 
amplio dentro del ámbito regional en el que se define. Nacida como un mecanismo para delimitar fronteras, encuadra su misión en la lucha contra los tres males y luego la "subcontrata" a una agencia subsidiaria para hacerse cargo de una misión fundamental en todas las asociaciones asiáticas: el fomento de las medidas de confianza mutua.

La OCS se ha convertido en el foro de referencia asiático, aunque sólo sea por la importancia de sus socios. A pesar de la ausencia de Turkmenistán, reúne dentro de su seno una serie de capacidades que la hacen única en el mundo. El potencial que atesora es, sin embargo, todavía mucho mayor ya que incluye entre sus países candidatos a la adhesión a India, Irán, Pakistán y Mongolia.

No es necesario enfatizar mucho las implicaciones que tendría una alianza real de todas estas naciones. A pesar de que las posibilidades de que llegue a materializarse parecen remotas hoy por hoy (y, desde luego, los esfuerzos de terceros países se centran en que así sea), la suma de los recursos de todo tipo que aportaría dicha unión a un ente que las agrupase justificaría probablemente una revisión del concepto de Tierra Corazón de MacKinder.

Aunque existe una componente económica de importancia creciente en la Organización, dentro del ámbito de la seguridad y la defensa, es importante resaltar los ejercicios militares que tienen lugar en el seno de la OCS. Los "Peace Mission" son, teóricamente, ensayos militares tendentes a la lucha contra el terrorismo que deben permitir la coordinación de los distintos ejércitos y de sus mandos. La edición de 2007 se celebró en Rusia ${ }^{16}$ con la participación, por primera vez, de 4.000 efectivos chinos. La edición del 2010, escenificada en Kazajstán, contó con la participación de todos los socios menos Uzbekistán y demostró que la capacidad china para la organización de las fuerzas utilizando el sistema de "operaciones en red" está muy por encima de la de sus socios y que el diferencial de calidad se está ensanchando su favor. Los ejercicios suponen un enorme esfuerzo en cuanto a las gestiones previas de diseño y al establecimiento de contactos de alto nivel y cuarteles generales ad-hoc para su desarrollo.

\section{Fuerzas Armadas}

\section{1. Kazajstán}

Los recientes acontecimientos en Kazajstán ${ }^{17}$ ponen de relieve la verdadera dimensión del problema de la seguridad en Asia Central. Mucho más allá de la simple defensa de los intereses nacionales respecto de actores estatales potencialmente hostiles, el riesgo se centra, cada vez más, en la amenaza que suponen los actores no estatales y los intereses de corporaciones y grupos sociales. Las Fuerzas Armadas kazajas - igual que las de la mayor parte de las repúblicas centroasiáticas - son, fundamentalmente, una herencia de la etapa soviética y responden mejor a las amenazas convencionales que a las asimétricas. Incluso las recientes adquisiciones de buques por parte de Astana con vistas a la protección de sus intereses en el Caspio adquieren dimensiones que los hacen poco eficientes en la lucha contra ataques terroristas.

\footnotetext{
16 Concretamente en Chelíabinsk.

17 Leonard, Peter: "Deadly riots challenge Kazakhstan", CNS News, 26 de diciembre de 2011, en http://cnsnews.com/news/article/deadly-riots-challenge-kazakhstan-stability.
} 
Grupos como Jund-al Khilafah, desconocidos hace muy poco tiempo, han ganado notoriedad en los últimos meses con ataques letales en el oeste del país. La preocupación del Gobierno se centra en su neutralización y en la pacificación de las protestas laborales sin que éstas desemboquen en baños de sangre que puedan recordar episodios similares en la región ${ }^{18}$.

No obstante, estas circunstancias no deben empañar el hecho de que Kazajstán es, hoy por hoy, el país de referencia de la región. Su espectacular crecimiento económico y su implicación en numerosas iniciativas internacionales lo convierten en un caso único en la zona. La presidencia de la Organización para la Seguridad y Cooperación en Europa (OSCE) que ostentó recientemente ${ }^{19}$ o la Presidencia del Consejo de Ministros de Exteriores de la Organización de la Conferencia Islámica, son todo un símbolo de su liderazgo y su compromiso en temas de seguridad y de su voluntad de implicación en la gobernanza global.

Más allá de la mera constatación de que, siguiendo la pujanza de su economía, Kazajstán está siendo capaz de diseñar unas Fuerzas Armadas que no estén condicionadas por la organización y los medios heredados de la Unión Soviética - caso prácticamente único en la región - lo más significativo es la proyección global de su política que esto permite y su papel hegemónico y de corredor estratégico a nivel regional ${ }^{20}$.

Astana mantiene una estrecha relación en materia de defensa con la Federación Rusa. El 25 de mayo de 1992 ambos gobiernos firmaban el Tratado de Amistad, Cooperación y Asistencia Mutua. Posteriormente se ratificó y amplió con la "Declaración de la Federación Rusa y la República de Kazajstán sobre la Amistad Eterna y la Cooperación en el siglo XXI" de julio de 1998. Tratados similares de "amistad eterna" han sido suscritos también con otras Repúblicas ex soviéticas (Uzbekistán y Kirguistán).

La renuncia a conservar el arsenal nuclear que estaba desplegado en su territorio tras la disolución de la URSS supuso también la extensión del paraguas nuclear ruso a todo el territorio de Kazajstán; al mismo tiempo se intercambiaron garantías con europeos y norteamericanos en el mismo sentido.

La gran cantidad de ejercicios y maniobras combinadas en las que participan las Fuerzas Armadas kazajas dentro de multitud de foros es una muestra más de la voluntad modernizadora de Astana respecto de sus ejércitos. Sólo en 2009 estos ejercicios y maniobras supusieron cincuenta y dos participaciones con un incremento de dieciocho respecto del año anterior. En muchos casos, el escenario de estos ensayos fue el mismo Kazajstán. La temática es tan variada como lo es el espectro de misiones posibles.

A pesar de todo, el foco de la atención kazaja en cuanto a la seguridad está puesto en su zona más occidental. No sólo por cuanto los movimientos sociales ${ }^{21}$ internos son más intensos en esa zona sino porque sus intereses económicos se basan, en muy buena medida, en los recursos de que dispone esa región. El desarrollo creciente de la flota del Caspio y las declaraciones respecto de la seguridad de sus instalaciones energéticas, tanto on-shore y off-

\footnotetext{
18 Como la llamada "masacre de Andiyán” en Uzbekistán.

19 Lillis, Joanna: "Kazakhstan: OSCE Differences Emerge During Astana Summit", Eurasianet.org, 1 de diciembre de 2011, en http://www.eurasianet.org/node/62480.

${ }^{20}$ Muzalevsky, Roman: "Kazakhstan - From Regional Discourse to Global Security", ISN Insights, 21 de marzo de 2011, en

http://www.isn.ethz.ch/isn/Current-Affairs/ISN-

Insights/Detail?lng=en\&id=127821\&contextid734\%20=127821\&contextid735=127552\&tabid=127552.

21 Kucera, Joshua: “Kazakhstan Opens Naval Air Base, Intimidates Strikers?”, The Bug Pit-Eurasianet.org, 6 de Julio de 2011, en http://www.eurasianet.org/node/63813.
} 
shore, frente a ataques terroristas no terminan de esconder completamente la ampliación de los horizontes de sus intereses. Su interés en el desarrollo y participación en el proyecto $\mathrm{Nabucco}^{22}$ junto a Azerbaiyán ${ }^{23}$ implica una posición firme más allá de las pocas millas que sus patrulleros le permitían adentrarse en el mar hasta recientemente ${ }^{24}$.

La proyectada construcción de varias $\operatorname{corbetas}^{25}$ y la adquisición de fragatas ${ }^{26}$ de Rusia dará a Astana la capacidad de proteger sus plataformas, pero también de influir en el Caspio y certificar su posición dominante en Asia Central. Las 17 patrulleras que alinea hasta el momento se encuentran mucho más limitadas en cuanto a alcance y capacidad de hacer sentir sus efectos.

\begin{tabular}{|c|c|c|c|}
\hline Tipo & Modelo & Cantidad & Observaciones \\
\hline Patrullera & Almaty & 4 & \\
\hline Patrullera & Dauntless & 1 & \\
\hline Patrullera & Guardian & 5 & \\
\hline Patrullera & Sea Dolphin & 3 & \\
\hline Patrullera & Turk (AB25) & 2 & \\
\hline Patrullera & Zhuk & 2 & \\
\hline
\end{tabular}

Buques de la Armada de Kazajstán. Fuente: Elaboración propia a partir de la base de datos de Jane's Defence.

\footnotetext{
22 El Nabucco es un proyecto de gasoducto que llevaría el gas azerí hasta Europa sin pasar por la Federación Rusa sino a través de Turquía. Una posible extensión incluiría tramos submarinos bajo el Caspio para recoger el gas kazajo y turkmeno. Recientemente, sin embargo, parece haber sufrido un revés importante por el acuerdo alcanzado por Azerbaiyán y Turquía para la construcción de un proyecto alternativo.

23 “Azerbaijan, Kazakhstan to Agree on Navy Cooperation”, Naval Today, 29 de junio de 2011, en http://navaltoday.com/2011/06/29/azerbaijan-kazakhstan-to-agree-on-navy-cooperation/.

24 Kucera, Joshua: “Kazakhstan Gets Jump on Caspian Naval Race”, Eurasianet.org, 23 de Julio de 2010, en http://www.eurasianet.org/node/61386.

25 Kazajstán había previsto su adquisición pero ha decidido, finalmente que las fabricaría en sus propios astilleros.

26 Algunas fuentes (ver "Armed Forces of the Republic of Kazakhstan"m Invisionfree, en http://s9.invisionfree.com/21c/ar/t8029.htm) hablan de una fragata de la clase Gepard-1 y otras cuatro del tipo 053H3 equipadas con sistemas de guerra electrónica y antiaérea de procedencia rusa.
} 
Las fuerzas terrestres, agrupadas en cuatro Mandos Regionales y un Mando de Movilidad Aérea (ver figura). De ellos, el Mando basado en la capital tiene funciones de reserva estratégica.

\begin{tabular}{|c|c|c|c|}
\hline Tipo & Modelo & Cantidad & Observaciones \\
\hline Carro de combate & $\mathrm{T}-72$ & 980 & \\
\hline Veh. Reconocimiento & BRDM & 140 & \\
\hline Veh. Reconocimiento & BRM & 140 & \\
\hline Veh. Blind. Comb. Infantería & BTR-80 & 90 & \\
\hline Veh. Blind. Comb. Infantería & BMP-1 & 730 & \\
\hline Veh. Blind. Comb. Infantería & BMP-2 & 700 & \\
\hline Transporte Personal Infantería & MT-LB & 180 & \\
\hline Transporte Personal Infantería & BTR-70/80 & 190 & \\
\hline
\end{tabular}

Vehículos de las fuerzas terrestres de Kazajstán. Fuente: Elaboración propia a partir de la base de datos de Jane's Defence.

A pesar de los lazos que unen a Kazajstán con su vecina Rusia y de que la práctica totalidad del material militar que posee es de procedencia rusa, Astana se ha asegurado de mantener vínculos estrechos con los Estados Unidos y con Europa. Algunos de sus oficiales han recibido formación en Norteamérica y se han realizado ejercicios con participantes de ambas naciones. Desde hace ya varios años, Kazajstán viene tomando parte, de forma más o menos regular, en los despliegues multinacionales que, bajo los auspicios de las Naciones Unidas, ha liderado Washington ${ }^{27}$.

Así, en Almaty se estableció un Centro de Entrenamiento de la Brigada de Fuerzas de Mantenimiento de la Paz kazajas (KAZBRIG) ${ }^{28}$. La Brigada es el resultado de la evolución del Batallón de Fuerzas de Mantenimiento de la Paz (KAZBAT) creado inicialmente.

\footnotetext{
27 McDermott, Roger N. and Col. Mukhamedov, Igor: “Kazakhstan's Peacekeeping Support in Iraq", Central Asia-Caucasus Institute Analyst, 28 de enero de 2004, en http://www.cacianalyst.org/?q=node/1809/print.

28 Shoemaker, Julie: "Peacekeeping Brigade Training Center Opens in Kazakhstan", US Army Corps of Engineers News Release, 21 de Julio de 2010, en http://www.tam.usace.army.mil/MED10-07-21-03.asp.
} 


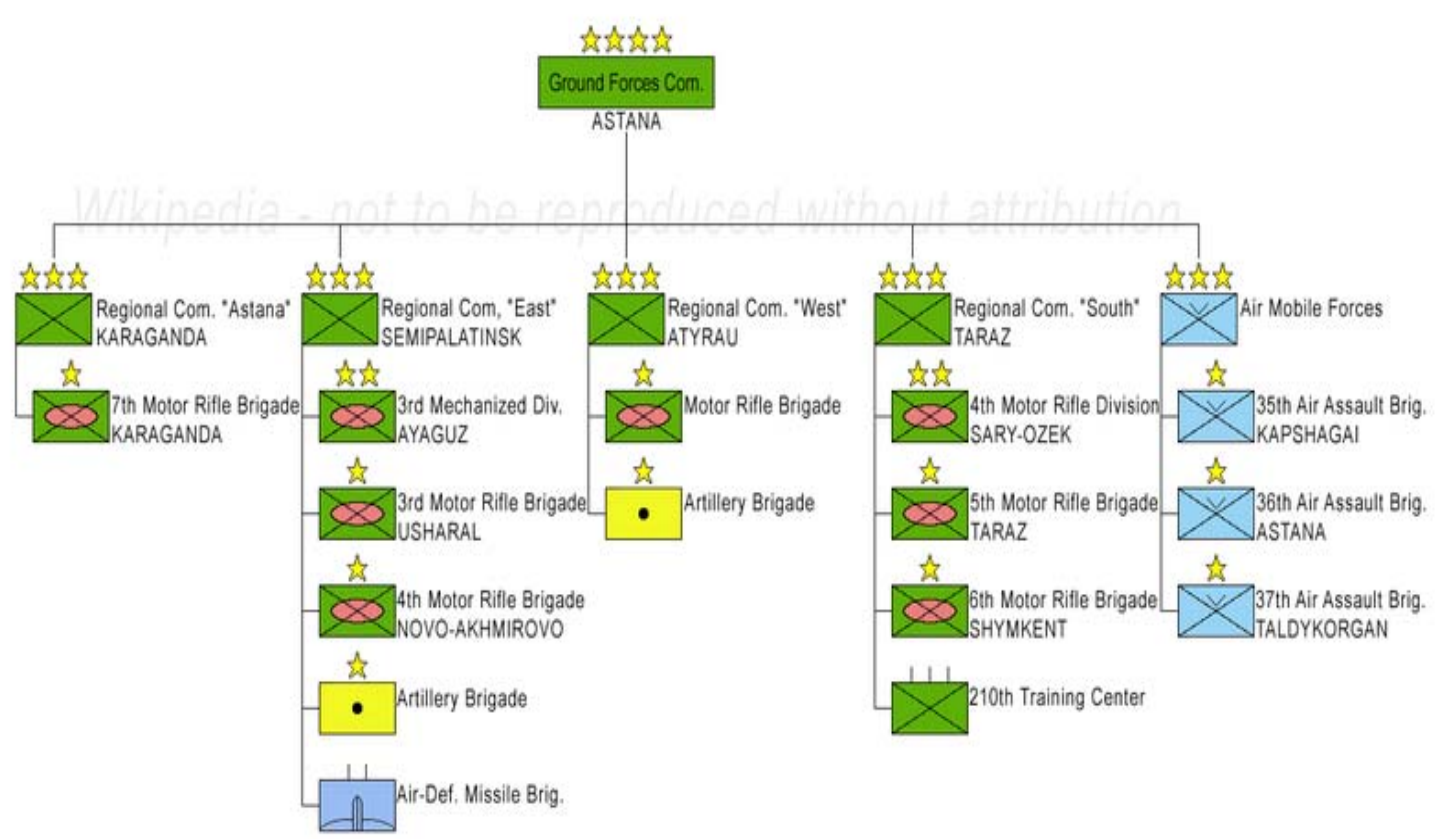

Organigrama de las fuerzas terrestres de Kazajstán. Fuente: “Armed Forces of the Republic of Kazakhstan"m Invisionfree, en http://s9.invisionfree.com/21c/ar/t8029.htm.

La aviación kazaja dispone del MiG-31 ${ }^{29}$ como su avión más moderno. Esta plataforma es también la más avanzada de la que dispone cualquiera de los países de Asia Central. La distribución del número de vectores de cada tipo demuestra un desequilibrio claro hacia la aviación de caza y de apoyo cercano más característica de una región periférica de la Unión Soviética que de un Estado moderno. De hecho, el despliegue mismo de las fuerzas sugiere un arco defensivo hacia el flanco oriental y sur y un vacío casi total en el norte y oeste.

\begin{tabular}{llll}
\hline Tipo de aeronave & Modelo & Número & Observaciones \\
\hline Caza & MiG-29/MiG-29UB & 39 & \\
\hline Caza & MiG-25 & 16 & \\
\hline Caza & MiG-31/MiG-31BM & 42 & 10 Remodelación \\
\hline Caza-bombardero & $\mathrm{Su}-24$ & 14 & \\
\hline Caza-bombardero & $\mathrm{Su}-27$ & 25 & \\
\hline Bombardero táctico & $\mathrm{Su}-25$ & 14 & \\
\hline Intel/Rec/Vigilancia & $\mathrm{Su}-24 \mathrm{MR}$ & 12 \\
\hline Transporte pasajeros & $\mathrm{Tu}-154$ & 1 \\
\hline
\end{tabular}

${ }^{29}$ Foxhound en terminología de la OTAN. 


\begin{tabular}{llll}
\hline Transporte ligero & Tu-134 & 2 & \\
Entrenamiento & L-39 & 12 & \\
\hline Entrenamiento & Yak-18 & 4 & \\
\hline Helicóptero ataque & Mi-24V & $40+$ & En mejora \\
\hline Hel. Transporte medio & Mi-171V5 & 20 & \\
\hline Hel. Transporte medio & Mi-8 & 50 & \\
\hline
\end{tabular}

Aeronaves de las Fuerzas Aéreas de Kazajstán. Fuente: Elaboración propia a partir de la base de datos de Jane's Defence.

Este vacío se rompe en los últimos tiempos con el despliegue aeronaval en Aktau encaminado a controlar y defender los recursos y los accesos de la región del Caspio. Un reforzamiento del papel de la OCS podría llevar a un redespliegue más centrado en aquellas zonas en las que se concentran la mayor parte de los intereses kazajos.

El hecho de que Kazajstán disponga del sistema antiaéreo S-300, de fabricación rusa y relativamente limitada difusión exterior, es significativo del papel prioritario que tiene el país para Moscú y de la alianza que mantienen en la defensa anti misil en la región. El S-300 es uno de los sistemas más avanzados del mercado. Recientemente alcanzó notoriedad por la negativa de Moscú a servir el pedido pendiente desde hace años que había hecho Teherán. El embargo de armamento a Irán y posibles presiones internacionales estarían detrás del veto a este tipo de ventas.

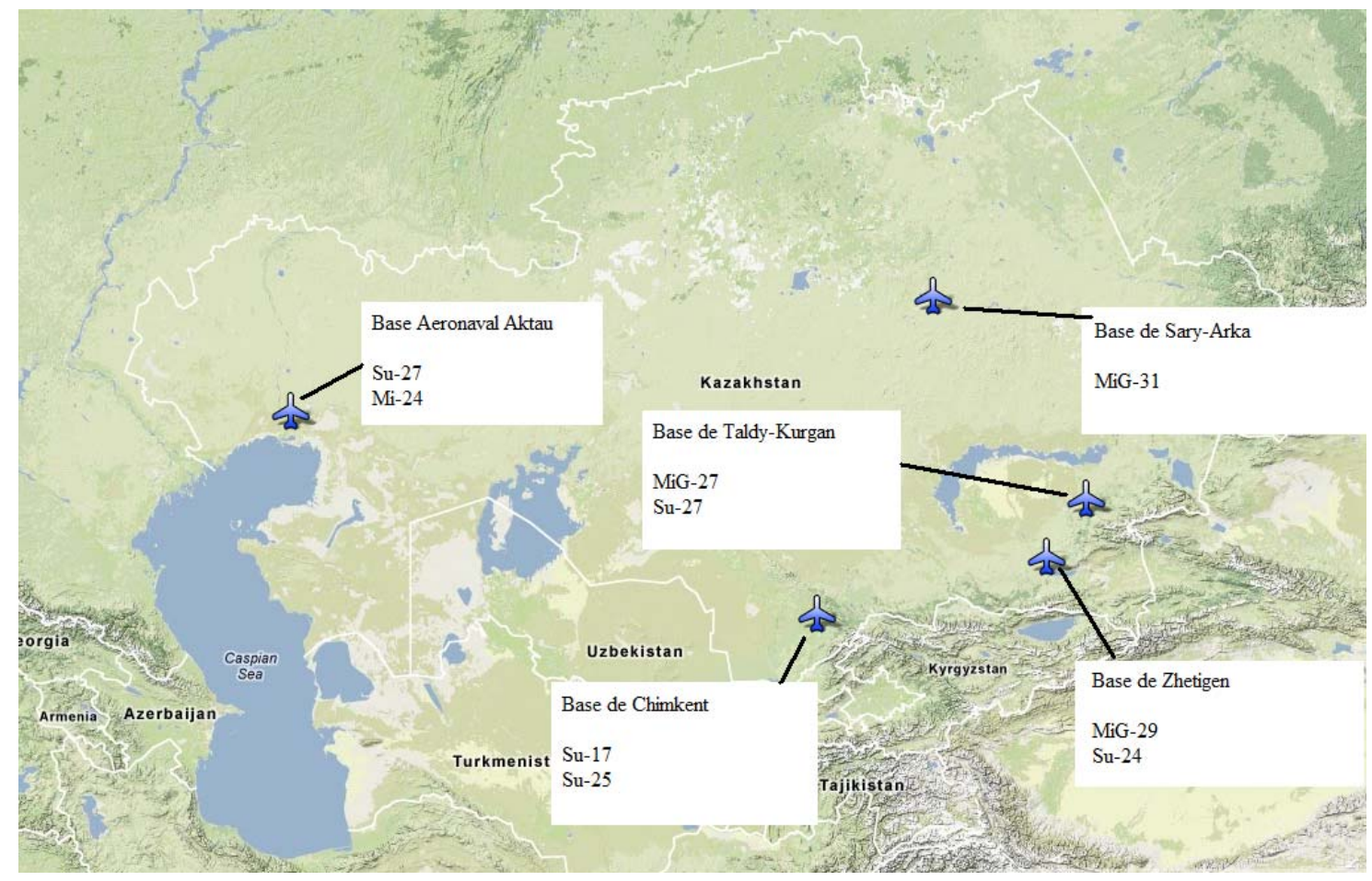

Despliegue de las Fuerzas Aéreas de Kazajstán. Fuente: Elaboración propia. 


\section{2. Uzbekistán}

Uzbekistán era la referencia de Moscú en la región durante la dominación soviética. Taskent se convirtió en la capital cultural y económica de la zona y los uzbekos, que suponían en aquel momento prácticamente la mitad de la población de Asia Central, la etnia dominante.

$\mathrm{Si}$, en general, todas las repúblicas centroasiáticas compusieron sus Fuerzas Armadas sobre las unidades soviéticas asentadas en sus respectivos territorios, el caso de Uzbekistán es particularmente significativo en tanto que existe una larga tradición de asentamientos militares de los sucesivos imperios regidos desde Moscú en este país. Tanto los zares como los soviets vieron en Taskent la sede ideal para estacionar sus cuarteles generales en Asia Central. Sólo en momentos de especial actividad - como durante las tensiones con China - se reforzó la presencia en la zona desdoblando la responsabilidad entre el área del Caspio y la parte más oriental de la región; al Distrito Militar del Turkestán con sede en Taskent se unió otro con base en Kazajstán que cubría la región fronteriza con China.

De este modo, existe una línea centenaria que conecta las sedes del Mando de la región en Uzbekistán y, de resultas de ello, las Fuerzas Armadas uzbekas no son sólo las más numerosas, sino también las que menos deficiencias presentan de todas ellas. Si tenemos en cuenta que la retirada soviética de Afganistán fue uno de los detonantes de la disolución de la Unión Soviética y se sitúa temporalmente como un precedente inmediato de la misma, se comprende que, en el momento de la transición, las unidades estacionadas en Uzbekistán estuviesen entre las más curtidas y experimentadas de entre todas las del Ejército Rojo.

La propia percepción de su identidad, su relativa importancia y el comprensible deseo de reafirmar su independencia se tradujo de forma inmediata en una errática política de alianzas y acuerdos en Taskent. Esto se refleja en su no inclusión en el grupo de los "Cinco de Shanghái" y en su inclusión posterior en la Organización para la Cooperación de Shanghái o en su dubitativa actitud respecto de la Organización del Tratado de Seguridad Colectiva. Su posición central entre las cinco repúblicas (pero sin frontera con China ni el Caspio), su población e influencia en el resto de los países a través de minorías étnicas en muchos de ellos, hacen de Uzbekistán un actor clave en la región.

En una muestra de la orientación hacia el interior de la seguridad, el Ejército se distribuye en cuatro Distritos Militares ${ }^{30}$ más uno central en la capital.

Sin duda, el Valle de Fergana constituye el punto más caliente, no sólo del país sino de toda la región, en cuanto a los conflictos de intereses. La zona constituye el enclave más fértil de la región y está dividida - casi de forma maquiavélica - entre el mismo Uzbekistán, Tayikistán y Kirguistán. La mezcla étnica, potencialmente explosiva de por sí, no está siquiera delimitada por las fronteras de sus propios países sino repartida por todo el valle. La competencia por los ricos recursos agrícolas y, sobre todo, por el acceso a las aguas del Syr Daria no es nueva, pero la disolución de la supervisión de Moscú deja solos al resto de los actores en su reparto. No es menos cierto que la introducción del cultivo extensivo del algodón por los soviéticos hizo que los problemas medioambientales y de reparto de agua se exacerbaran y deviniesen en una catástrofe rio abajo y un casus belli con el resto de los estados riparios.

\footnotetext{
${ }^{30}$ Según la publicación especializada Jane’s
} 
La llamada "masacre de Andiyán", producida en 2005 en la capital uzbeca del valle cuando las Fuerzas Armadas tomaron parte en el control de unas protestas ciudadanas con el resultado de varios centenares de muertos, no sólo tuvo serias consecuencias para las relaciones de Uzbekistán con Occidente sino que refleja de forma meridiana la inadecuación del medio - las Fuerzas Armadas - a la misión que se les asigna. El embargo de armas decretado por la Unión Europea como consecuencia de esta acción tuvo, sin duda, un impacto relevante en la política de defensa de Uzbekistán y forzó su acercamiento a la Federación Rusa y a las organizaciones regionales con las consecuencias que veremos.

En cuanto a los medios disponibles para las Fuerzas Armadas, el número total de efectivos es de alrededor de 67.000 tropas, 50.000 de las cuales están encuadradas en la estructura de las fuerzas terrestres y las 17.000 restantes en las aéreas. Además de los cuadros permanentes, es obligatorio un servicio militar de un año a partir de los 18 años. Los ciudadanos permanecen disponibles hasta los cuarenta y nueve años de edad para su posible activación.

Además de las Fuerzas Armadas, Uzbekistán cuenta con hasta 20.000 efectivos entre la Tropas de Seguridad Interior y la Guardia Nacional.

\begin{tabular}{|c|c|c|c|}
\hline Tipo & Modelo & Cantidad & Observaciones \\
\hline Carro de combate & $\mathrm{T}-72$ & 70 & \\
\hline Carro de combate & $\mathrm{T}-64$ & 100 & \\
\hline Carro de combate & $\mathrm{T}-62$ & 170 & \\
\hline Veh. Reconocimiento & BRDM-2 & 13 & \\
\hline Veh. Reconocimiento & BRM & 6 & \\
\hline Veh. Blind. Comb. Infantería & BMD-1 & 120 & \\
\hline Veh. Blind. Comb. Infantería & BMD-2 & 9 & \\
\hline Veh. Blind. Comb. Infantería & BMP-2 & 270 & \\
\hline Transporte Personal Infantería & BTR-D & 50 & \\
\hline Transporte Personal Infantería & BTR-60 & 24 & \\
\hline Transporte Personal Infantería & BTR-70 & 25 & \\
\hline Transporte Personal Infantería & BTR-80 & 210 & \\
\hline
\end{tabular}

Vehículos de las fuerzas terrestres de Uzbekistán. Fuente: Elaboración propia a partir de la base de datos de Jane's Defence. 
Como es habitual en la región, el carro de combate más representativo es un nada moderno T72 de procedencia soviética. Aparte de las 70 unidades de este modelo que figuran en el inventario, disponen también de otros cien T-64 y 170 T-62 de, incluso, peores características. Junto a los carros de combate, casi quinientas piezas de artillería de todo tipo completan la dotación de las fuerzas terrestres.

La artillería antiaérea está integrada, lógicamente, con la Fuerza Aérea, aunque está formada por anticuados modelos S-75 Dvina $^{31}$ y S-125 Pechora $^{32}$ y por los S-200 Angara $^{33}$, claramente inferiores a los S-300 kazajos.

El resto de la aviación está dotada, fundamentalmente, de los mismos tipos de aviones y helicópteros que estaban en servicio cuando accedió a la independencia. En esencia se trata de los medios de que disponía el $49^{\circ}$ Ejército Aéreo soviético y dos Brigadas independientes. Este hecho hace que su Fuerza Aérea sea mucho más moderna y numerosa que la de la mayor parte de sus vecinos.

\begin{tabular}{|c|c|c|c|}
\hline Tipo de aeronave & Modelo & Número & Observaciones \\
\hline Caza & MiG-29/MiG-29UB & 30 & Otras fuentes: 60 \\
\hline Caza-bombardero & $\mathrm{Su}-17 \mathrm{M} / \mathrm{Su}-17 \mathrm{MZ} / \mathrm{Su}-17 \mathrm{UM} 3$ & 26 & Reserva \\
\hline Caza-bombardero & $\mathrm{Su}-24$ & 23 & Rva. Estratégico \\
\hline Caza-bombardero & Su-27/Su-27UB & 25 & \\
\hline Bombardero táctico & $\mathrm{Su}-28 / \mathrm{Su}-25 \mathrm{Bm}$ & 20 & \\
\hline Alerta / Transporte & An-12/An-12PP & 26 & \\
\hline Guerra electrónica & $\mathrm{Su}-24 \mathrm{MP}$ & 11 & \\
\hline G. electrónica / Transp. & An-26/An-26RKR & 13 & \\
\hline Transporte estratégico & Il-76 & 6 & No figura en Jane's \\
\hline Transporte ligero & An-24 & 1 & \\
\hline Transporte ligero & Tu-134 & 1 & \\
\hline Entrenamiento & L-39 & 5 & 9 en reserva \\
\hline Helicóptero ataque & $\mathrm{Mi}-24$ & 29 & \\
\hline Helicóptero mando & Mi-6 & 2 & \\
\hline Hel. Transporte pesado & Mi-6 & 27 & \\
\hline
\end{tabular}

${ }^{31}$ Que corresponde con la denominación SAM-2 Guideline de la OTAN

32 Que corresponde con la denominación SAM-3 Goa de la OTAN

33 Que corresponde con la denominación SAM-5 Gammon de la OTAN 
Hel. Transporte pesado Mi-26 1

Hel. Transporte medio Mi-8 52

Aeronaves de las Fuerzas Aéreas de Uzbekistán. Fuente: Elaboración propia a partir de la base de datos de Jane's Defence.

El material más moderno está formado por el MiG-29 y el extremadamente ágil Sukhoi Su-27 de superioridad aérea y del cual dispone de veinticinco unidades en su inventario. Uzbekistán dispone incluso de 23 Sukhoi Su- $24^{34}$ de bombardeo estratégico, si bien están actualmente es reserva y no se encuentran operativos. El apoyo cercano podría correr a cargo de los 20 Sukhoi Su-25 o de los Su-17 disponibles en reserva. La estrella de la aviación de transporte es el Illyouschin I1-76, estratégico de largo alcance, de los cuales opera seis aparatos. Junto a éstos, completan la flota los Antonov An-12, An-24 y An-26. En cuanto a los medios de ala rotatoria, Taskent tiene un amplio abanico de modelos de helicópteros, desde los Mi-24 de ataque y Mi-6 de transporte pesado hasta los Mi-8 y Mi-26 de transporte medio. Las fuentes discrepan ampliamente en cuanto al número de aparatos de cada tipo que estarían en disposición de ser puestos en vuelo en caso de necesidad.

La dubitativa política de alianzas que, decíamos, mantuvo Uzbekistán durante los primeros años después de su independencia comenzó con un cierto alejamiento de Moscú, que se vio reforzado tras los atentados terroristas del once de septiembre de 2001 en Washington, Nueva York y Pennsylvania, por el ofrecimiento de colaboración a los Estados Unidos en su lucha contra el terrorismo global.

Como resultado del ofrecimiento, la USAF inició un contrato de leasing por la Base Aérea de Karshi-Khanabad (de ahí la denominación que recibió de los americanos, K2, y no en alusión a la segunda cumbre del Himalaya) en el sur del país, próxima a la frontera con Afganistán. Encargado de la gestión de las operaciones de vuelo y apoyo en la base estuvo el $416^{\circ}$ Grupo Aéreo de Operaciones Expedicionarias norteamericano. De forma simultánea operaba desde la misma Base por parte uzbeca la $60^{\mathrm{a}}$ Brigada Mixta de Aviación, dotada con Su-24 y Su-27. De resultas de la "masacre de Andiyán" y de las sanciones occidentales contra Uzbekistán, éste terminó por integrarse en la OCS y solicitar la evacuación de las fuerzas norteamericanas que, finalmente, dejaron la base en noviembre de ese mismo año 2005.

\section{3. Tayikistán}

El total de las Fuerzas Armadas de Tayikistán ${ }^{35}$ es de sólo 8.800 efectivos. Del total de los mismos, 7.300 pertenecen a las fuerzas terrestres y los 1.500 restantes a la Fuerza Aérea. Evidentemente, siendo este uno de los países que necesitan transitar, al menos, por otros dos antes de alcanzar el mar, los tayikos no tienen fuerzas navales. Sin embargo, su mayor fuente de riqueza y el factor polemológico más importante del país es el agua; tanto para producción hidráulica como para riego. Las fuerzas paramilitares son casi tan numerosas como las regulares y añaden otras 7.500 cabezas.

Estos datos se reflejan en un presupuesto de defensa que varía entre el 1,8\% y el 2,2\% y que supone algo más de ochenta millones de dólares anuales.

\footnotetext{
${ }^{34}$ Fencer, según la denominación OTAN.

35 De acuerdo siempre con los datos proporcionados por Jane's
} 
Tayikistán, la única de las cinco repúblicas con un componente persa predominante, es también la más pobre de todas ellas. Su proximidad étnica y sus lazos con Afganistán suponen un problema para la seguridad de todas las naciones de Asia Central ya que la incapacidad o falta de voluntad de sus fuerzas para mantener un control sobre las fronteras - tanto hacia el sur de entrada como en el resto de los flancos de salida - convierte al país en una vía de tránsito preferida por los narcotraficantes afganos y, lo que es igual de peligroso, para los radicales islamistas que pretenden operar en toda la región.

Tipo Modelo Cantidad Observaciones

$\begin{array}{lll}\text { Carro de combate } & \mathrm{T}-72 & 30\end{array}$

Carro de combate $\mathrm{T}-62$ 7

Veh. Blind. Comb. Infantería BMP-1 8

Veh. Blind. Comb. Infantería

BMP-2 15

Transporte Personal Infantería BTR-60/70/80 23

Vehículos de las fuerzas terrestres de Tayikistán. Fuente: Elaboración propia a partir de la base de datos de Jane's Defence.

Esta preocupación se refleja en la presencia de unidades rusas en el país en una cantidad y, sobre todo, calidad, superior a las indígenas. Mientras el número total de militares rondaría los 5.000 a 5.500, los medios desplegados serían de una calidad muy superior a la de los que tienen los tayikos. Los rusos están establecidos en el mismo Dusambé y en las Bases de Kulob y Qurghonteppa. Las fuerzas terrestres constan de una División incompleta (la 201 División) con una cincuentena de carros de combate del modelo $\mathrm{T}-72^{36}$ como su principal recurso ofensivo, acompañados de 300 vehículos blindados de transporte de tropas y un centenar de piezas de artillería autopropulsada. El apoyo aéreo está proporcionado por cinco aviones reactores Sukhoi $\mathrm{Su}-25^{37}$ y cuatro helicópteros Mi- $8^{38}$.

Fuentes militares especulan con la posibilidad de que India esté operando o en condiciones de operar alrededor de una docena de MiG-29 $9^{39}$ desde una Base Aérea tayika. Mientras que Jane's, publicación de referencia en el mundo militar, afirma que se trataría de la Base de Farkhar (o Farkhor), a sólo dos kilómetros de la frontera afgana, parece más probable que los hindúes hubiesen preferido aprovechar la inversión realizada en las mejoras de la Base de Ayni, próxima a Dusambé. Esta Base, sin embargo, era objeto recientemente de una oferta tayika a Moscú según la cual los rusos apoyarían a aquellos en su disputa con Uzbekistán respecto a las diferencias que mantienen sobre el volumen de agua disponible para

\footnotetext{
36 El T-72 es, técnicamente, un carro de combate relativamente capaz para su generación. Superado ya por diseños como el T-80 y el T-90, sigue en servicio en numerosos ejércitos de todo el mundo. Se estima que solo la Federación Rusa mantiene varios miles entre carros activos y unidades en reserva.

37 "Frogfoot" en nomenclatura OTAN

38 "Hip" en nomenclatura OTAN

39 "Fulcrum" en nomenclatura OTAN
} 
los uzbecos y la construcción de nuevas presas y plantas hidroeléctricas en el país. A cambio del apoyo ruso, éstos obtendrían un leasing de la Base.

Lo más probable, en cualquier caso, es que no exista una presencia permanente de la Fuerza Aérea India en Tayikistán, más por la oposición rusa a la competencia de cualquier otra potencia que por el peligro de escalada que podría suponer la ubicación de cazas indios a la espalda de Pakistán y a unos pocos minutos de vuelo de él. En cualquier caso, tanto Tayikistán como la misma India han desmentido reiteradamente dicha presencia - que, por otro lado, sería harto difícil de ocultar, de ser cierta.

En comparación con las fuerzas extranjeras en su territorio, las unidades tayikas apenas si pueden alinear 37 carros de combate, 30 del tipo T-72 y otros 7 muy veteranos T-62. La división que hace el Ejército de Tayikistán de sus fuerzas en cinco Brigadas y un Regimiento (de misiles superficie-aire) no debe llevarnos a establecer una comparación con unidades equivalentes de países occidentales.

El nivel de preparación de las fuerzas y su compromiso tampoco pueden considerarse óptimos. Su papel, aparte de representativo, está más enfocado hacia el interior del país que hacia sus vecinos; a pesar de poseer una extensa frontera con Afganistán y de compartir varios diferendos con Uzbekistán. En esa labor de control interno compartiría funciones con otras 3.800 tropas del Ministerio del Interior, 1.200 representantes de la Guardia Nacional, los 2.500 que aporta el Ministerio de Emergencias y los componentes de la Guardia de Fronteras.

\begin{tabular}{|c|c|c|c|}
\hline Tipo de aeronave & Modelo & Número & Observaciones \\
\hline Transporte ligero & Tu-134 & 1 & \\
\hline Helicóptero ataque & Mi-24 & 4 & \\
\hline Hel. Transporte medio & Mi-8/Mi-17TM & 12 & \\
\hline
\end{tabular}

Aeronaves de las Fuerzas Aéreas de Tayikistán. Fuente: Elaboración propia a partir de la base de datos de Jane's Defence.

Su Fuerza Aérea se limita a unos viejos aviones Tupolev Tu- $134 \mathrm{~A}^{40}$ de transporte y a un escuadrón mixto de helicópteros Mi-24 de ataque y Mi-8 y su variante Mi-17TM ${ }^{41}$ de transporte de tropas. La capacidad de todos ellos es muy limitada incluso en caso de que el estado de mantenimiento del material y entrenamiento de las tripulaciones respondiera a unos estándares de calidad más exigentes.

Dos veces al año, en primavera y otoño, Tayikistán pone en marcha su proceso de conscripción para reclutar a entre quince y dieciséis mil jóvenes al año para un servicio militar obligatorio de dos años. La recluta se lleva a cabo entre aquellos con edades comprendidas entre los 18 y los 27 años. Ese margen situaría a unos 600.000 varones en condiciones de

\footnotetext{
40 Crusty en denominación OTAN.

${ }^{41}$ Hind, Hip y Hip $H$ respectivamente, en denominación OTAN.
} 
prestar servicio militar, de los que habría que deducir a los 150.000 declarados exentos ${ }^{42} \mathrm{o}$ que han retrasado su incorporación a filas. La égida de trabajadores que, sobre todo desde la Federación Rusa, sostiene un $40 \%$ de la economía tayika con sus remesas de dinero ocasiones, sin embargo, que otros 100.000 potenciales reclutas se encuentren fuera del país y no sean, por lo tanto, elegibles para prestar servicio. Como es evidente, de la cantidad remanente habrá que detraer aquellos que ya forman parte de la reserva militar u otros cuerpos.

\section{4. Kirguistán}

Un panorama muy similar al de Tayikistán presentan las Fuerzas Armadas kirguices. Con un total de 10.900 efectivos, 8.500 pertenecen a las fuerzas terrestres y los restantes 2.400 a la Fuerza Aérea.

El equipamiento es, no obstante, algo mejor y, sobre todo, mayor que el tayiko. Kirguistán cuenta con hasta 150 carros T-72 y 246 piezas de artillería, de las cuales 18 son unidades 2S1 Carnation autopropulsadas. Todo el material, con excepción de los morteros remolcados M-120 - fabricados en Israel - es de manufactura rusa, o procedente de la industria soviética.

\begin{tabular}{|c|c|c|c|}
\hline Tipo & Modelo & Cantidad & Observaciones \\
\hline Carro de combate & $\mathrm{T}-72$ & 150 & \\
\hline Veh. Reconocimiento & BRDM-2 & 30 & \\
\hline Veh. Blind. Comb. Infantería & BMP-1 & 230 & \\
\hline Veh. Blind. Comb. Infantería & BMP-2 & 90 & \\
\hline Transporte Personal Infantería & BTR-70 & 25 & \\
\hline Transporte Personal Infantería & BTR-80 & 10 & \\
\hline
\end{tabular}

Vehículos de las fuerzas terrestres de Kirguistán. Fuente: Elaboración propia a partir de la base de datos de Jane's Defence.

La naturaleza montañosa del país hace que la fuerza incluya la $1^{a}$ Brigada Motorizada de Fusileros que está especializada en actuaciones en este ambiente. Está basada en la ciudad de Osh. El tipo de amenazas que debe afrontar, terrorismo y narcotráfico, también aconsejaron la creación de la 25 $5^{\mathrm{a}}$ Brigada de Fuerzas Especiales "Escorpión", con base en Biskek. La

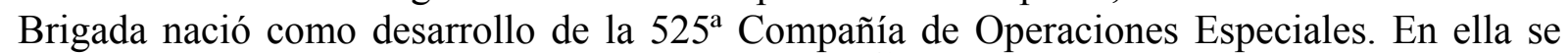
integran las mejores tropas y equipos disponibles ${ }^{43}$. Aparte de estas unidades, existe otra brigada en Koy-Tash y batallones independientes en Karakol y Naryn.

\footnotetext{
${ }^{42}$ Las causas de exclusión militar en Tayikistán son la enfermedad, el estar cursando estudios universitarios, el hecho de ser hijo único o el de ser padre de dos hijos.

${ }^{43}$ La Guardia Nacional kirguiz también tiene un batallón de fuerzas especiales aerotransportadas, el Pantera.
} 
La morfología del país y las inadecuadas comunicaciones implican la necesidad de dispersar las fuerzas para obtener una capacidad de reacción pronta y de disponer de un transporte aéreo de entidad suficiente como para salvar las distancias existentes entre los principales núcleos de población sin tener que transitar por las difíciles carreteras del país.

Las Fuerzas Aéreas tienen en su inventario restos de los 100 MiG-21 que adquirió en su día pero tanto su antigüedad como su estado de mantenimiento hacen muy dudoso que alguno pueda estar en condiciones de vuelo. El hecho de que dejasen de estar en servicio en la Federación Rusa hace dos décadas complica el sostenimiento del sistema de armas aunque, por otro lado, permite la utilización de piezas de los aviones retirados para la reparación de los kirguises. Mayor utilidad puede obtenerse de los cuatro Aero L-39 Albatros que mantiene en servicio la Fuerza Aérea Kirguiz. Este avión es, en realidad, un entrenador avanzado que puede ser utilizado para apoyo a operaciones en tierra convenientemente artillado. En cualquier caso, su reducido número implica que no más allá de uno o dos aviones estarán operativos en un momento dado.

\begin{tabular}{llll}
\hline Tipo de aeronave & Modelo & Número & Observaciones \\
\hline Caza & MiG-21 & 48 & 24 en reserva \\
\hline Transporte medio & An-12 & 2 & \\
\hline Transporte ligero & An-26 & 2 & 24 en reserva \\
\hline Entrenamiento & L-39 & 4 & \\
\hline Helicóptero ataque & Mi-24 & 9 & \\
\hline Hel. Transporte medio & Mi-8 & 23 & \\
\hline
\end{tabular}

Aeronaves de las Fuerzas Aéreas de Kirguistán. Fuente: Elaboración propia a partir de la base de datos de Jane's Defence.

La aviación de transporte de ala fija se compone de dos Antonov An-12 y otros dos An-26 $6^{44}$. Además de que ambos tipos de aviones son ciertamente veteranos y que su número los convierte en ineficientes por la carga logística que implica su sostenimiento casi individual, la reducida capacidad de carga que tienen - sobre todo en el caso de los An-26 - hace que resulten poco útiles para despliegues y que sus labores apenas si puedan limitarse a enlace y apoyo logístico puntual.

Como es habitual en estos países, la fuerza de helicópteros es la más interesante con los 9 Mi-24 y $23 \mathrm{Mi}-8^{45}$, de ataque y transporte respectivamente. Este contingente es el único con alguna capacidad real para moverse con libertad por todo el país. En cualquier caso, el grado de preparación de las tripulaciones de vuelo y de mantenimiento condiciona la operatividad de los aparatos más allá de lo que puedan ya hacerlo las condiciones meteorológicas y orográficas.

\footnotetext{
${ }_{44}$ Cub y Curl respectivamente, en denominación OTAN.

45 Algunos de éstos de la versión Mi-17.
} 
A estas fuerzas hay que añadir la Guardia de Fronteras, que cuenta con unos 5.000 componentes, las Tropas de Interior y la Guardia Nacional, con 3.500 y 1.000 respectivamente.

El servicio militar se presta durante un año desde el año 2004 en que se redujo desde los 18 meses anteriores. En 2009, el Presidente Bakiyev impulsó una ley por la que era posible eludir la obligación de pasar por filas previo pago de la cantidad de 250 dólares estadounidenses. El importe es elevado para el nivel de vida del país y, en realidad, suponía una exención sólo para las clases más pudientes. Un decreto presidencial acabó en julio de 2010 con esta práctica volviendo a instaurar la obligatoriedad de la conscripción. La Ley establece la disponibilidad para servir de todos los varones entre 15 y 49 años de edad.

Sin embargo, lo más significativo de Kirguistán no son sus propias Fuerzas Armadas sino la utilización que hace de sus bases y los acuerdos que mantiene con la Federación Rusa y con los Estados Unidos. En apenas unos kilómetros se encuentran la Base Aérea de Kant, ocupada por los rusos, y el llamado Centro de Tránsito de Manás, que utilizan los norteamericanos y, hasta hace poco también los españoles, como escala para el sostenimiento de sus fuerzas en Afganistán prácticamente desde el inicio de la campaña en 2.001.

El reciente anuncio del Gobierno kirguiz de que solicitaría a los Estados Unidos la evacuación de la Base de Manás - rebautizada como Centro de Tránsito como consecuencia de las negociaciones que siguieron a la renovación del leasing y a las presiones de Moscú para que se limitase la presencia norteamericana en la región - puede responder al renovado interés ruso en desalojar definitivamente a los americanos de Asia Central tanto como al deseo de Biskek de consolidar una posición negociadora más firme de cara a la siguiente renovación del contrato. Los ingresos que obtiene Kirguistán por el alquiler de ambas bases, supone un aliciente importante y una parte significativa de sus ingresos. En el caso de la de Manás, tras la renegociación de 2009, el incremento del precio del alquiler fue de cuarenta millones de dólares. La negociación vino precedida, también en aquella ocasión, de un anuncio de cierre de la Base.

En cualquier caso, la presencia rusa y norteamericana en el país supone un importante factor estabilizador.

El Centro de Tránsito de Manás ${ }^{46}$ ha jugado un papel muy relevante en el despliegue y sostenimiento de las fuerzas de la coalición que opera en Afganistán. Para España supuso un paso casi obligado para el personal y los suministros que llegaban por vía aérea, especialmente hasta que la ampliación de la pista de Herat permitió la llegada de aviones de gran envergadura directamente al Teatro de Operaciones. Manás es, al mismo tiempo, el aeropuerto más importante del país y el centro de operaciones de la $376^{\mathrm{a}}$ Ala Expedicionaria de los Estados Unidos, cuya misión consiste en facilitar el tránsito de tropas y enseres hacia y desde Afganistán.

La Base Aérea de Kant, a unas decenas de kilómetros al oeste, alberga a unos quinientos militares $\operatorname{rusos}^{47}$ y está dotada de cinco Sukhoi Su-25 $5^{48}$, aviones especializados en apoyo

\footnotetext{
46 Más información disponible en la página web del Centro de Tránsito de Manás en http://www.manas.afcent.af.mil/.

47 Puntualmente, se incrementó la cifra con otros 150 paracaidistas con motivo de la transición en el poder en el país con el acceso de Roza Ottumbayeva al mismo. La razón aducida fue favorecer la protección de los civiles rusos presentes en la región. Existe una importante componente de un 17\% de etnia rusa en Kirguistán.

${ }^{48}$ Frogfoot, en terminología OTAN.
} 
cercano y ataque al suelo, y dos helicópteros Mi-8 de enlace y apoyo. En 2009, la Federación Rusa firmó un acuerdo con Biskek para establecer una segunda base rusa en el sur del país. Kirguistán se estaría, pues, posicionando muy claramente del lado de los países más afines a Moscú.

Los principales retos de seguridad de Kirguistán son el radicalismo islámico, la violencia étnica y el tráfico de drogas. La entidad de sus Fuerzas Armadas y sus mismos intereses económicos condicionarían, en cualquier caso, sus relaciones con sus vecinos. Mientras Kazajstán, Uzbekistán ${ }^{49}$ y, desde luego, la República Popular China, tienen unos medios muy superiores, las relaciones con Tayikistán, al sur, son cordiales y los intereses respecto de la lucha antidroga y contra la amenaza yihadista compartidos por ambos.

El tránsito de droga procedente de Afganistán a través de su territorio conlleva, por otro lado, el incremento de la actividad del crimen organizado en el interior del país y fomenta la corrupción de la Administración. A este problema tenemos que añadir la proliferación de grupos islamistas radicales como Hizb ut-Tahrir (HuT), el Movimiento Islámico de Uzbekistán (MIU) y su rama de la Unión Yihadista Islámica (UYI). La mayor parte de estos grupos actúan en la que ya es, de por sí, la zona más inestable de la región - al tiempo que la más productiva - y escenario de frecuentes conflictos, el valle de la Fergana.

Se ha mencionado ya la importancia de las comunicaciones internas (y de su deficiente estado) como factor importante en la movilidad de las fuerzas. El relativo aislamiento en que viven una zonas respecto de otras propicia el establecimiento de poblaciones de etnias distintas en cada una de ellas. En la región sur tienden a concentrarse las minorías uzbeca y tayika dando lugar a tensiones étnicas en o alrededor de poblaciones meridionales como Osh o Jalal-Abbad.

La corrupción y brutalidad de las fuerzas policiales se dan por descontadas en el país, que sigue mirando hacia Rusia y Kazajstán como referentes y apoyos necesarios para su estabilidad.

La riqueza del subsuelo kirguiz, tanto en minerales ${ }^{50}$ como en hidrocarburos $^{51}$ puede excitar la codicia de sus vecinos o generar tensiones internas cuando la explotación de estos recursos pase a ser rentable en función de la evolución de los precios de dichas commodities.

\section{5. Turkmenistán}

Turkmenistán es el país más aislado y que menos relación tiene con los demás de la región. Tanto su situación estratégica como los recursos que alberga son de la máxima importancia. Su ubicación costera en el Caspio y su vecindad con Irán le confieren características muy peculiares que condicionan el desarrollo de sus Fuerzas Armadas. A pesar de su extensión, del total de su territorio, más del $80 \%$ está constituido por el Desierto del Karakum.

Por un lado, su condición de estado costero le permite $-\mathrm{y}$ obliga de algún modo - a disponer de algunos medios navales con los que atender a sus responsabilidades en su zona litoral y defender sus intereses en el Caspio. En este sentido, la disputada condición jurídica

\footnotetext{
49 Con quién firmó un acuerdo fronterizo en 2010.

50 Kirguistán tiene importantes yacimientos de oro, carbón, uranio y antimonio en cuya explotación está implicada muy directamente China y en donde existe una potencial cooperación con España.

51 Se estiman unas reservas de 224 millones de barriles de crudo y casi 21 millones de metros cúbicos de gas natural, ambos de compleja extracción y que requieren importantes inversiones.
} 
de las aguas del mismo y la entidad y relaciones que Turkmenistán mantiene con el resto de los estados costeros hace de su gestión algo particularmente complejo.

En la actualidad, Turkmenistán está en un proceso de transición desde la actual dependencia de las unidades navales de la Guardia de Fronteras hacia una Armada propiamente dicha. Los efectivos actuales son muy limitados y comprenden entre 500 y 700 hombres con base en el puerto de Turkmenbashy.

\begin{tabular}{|c|c|c|c|}
\hline Tipo & Modelo & Cantidad & Observaciones \\
\hline Carro de combate & $\mathrm{T}-72$ & 670 & \\
\hline Carro de combate & $\mathrm{T}-90 \mathrm{~S}$ & 10 & \\
\hline Veh. Reconocimiento & $\mathrm{BRDM} /-2$ & 170 & \\
\hline Veh. Blind. Comb. Infantería & BMP-1/2 & 930 & \\
\hline Veh. Blind. Comb. Infantería & BRM & 12 & \\
\hline Transporte Personal Infantería & BTR-60/70/80 & 829 & \\
\hline
\end{tabular}

Vehículos de las fuerzas terrestres de Turkmenistán. Fuente: Elaboración propia a partir de la base de datos de Jane's Defence.

En cuanto a los buques disponibles, su inventario apenas si está compuesto por media docena de patrulleros, uno adquirido a los Estados Unidos en mayo de 2000 y cinco Grift-T (Condor) de la clase Kalkan. El primero de ellos - con diferencia el más significativo - se denomina "Merjin" en la actualidad; se trata del antiguo "Point Jackson" norteamericano que estuvo basado en Massachussets entre 1970 y 2000, año de su transferencia a Turkmenistán, como queda dicho. El Merjin comparte las aguas del Caspio con otro buque de la misma clase, el S201 de la Armada de Azerbaiyán, desde el año 2003.

Durante años, los buques pertenecientes a Turkmenistán operaron de forma conjunta con los kazajos y los rusos dentro de la denominada Flotilla del Caspio. Ya se explicó que Kazajstán retiró su contribución para la formación de su propia Armada, aunque Ashjabat mantuvo su cooperación con los rusos dentro de la Flotilla en Astrakán durante un tiempo.

La opacidad de las compras de material militar en que Turkmenistán envuelve todas sus transacciones no permite confirmar si las tres corbetas de la clase Molniya que la Federación Rusa ha anunciado que iba a vender a una antigua república soviética tienen como destino la Armada de este país ${ }^{52}$

El grueso de los 22.000 efectivos totales de las Fuerzas Armadas turkmenas, 18.500, pertenecen al Ejército. Fundamentalmente desplegado en la franja litoral y en la frontera sur

\footnotetext{
52 Kucera, Joshua: "Russia selling warships to mistery Post-Soviet State, Maybe Turkmenistan", The Bug Pit Eurasianet.org, 21 de Julio de 2011, en http://www.eurasianet.org/node/63926.
} 
con Irán, es también heredero de las unidades soviéticas que estaban estacionadas en la república autónoma en el momento de su independencia; todas ellas de Infantería Motorizada.

De este modo, la 22 a División de Infantería Motorizada está acuartelada cubriendo la región litoral caspia, la $2^{\mathrm{a}}$ y $3^{\mathrm{a}}$ divisiones están en la frontera iraní, guardando el flanco sur de la antigua Unión Soviética y la $11^{\mathrm{a}}$ División protege el flanco tayiko.

Los analistas estiman que el estado de mantenimiento y preparación de las fuerzas turkmenas es muy deficiente, incluso comparado con sus homólogas de la región pero los sustanciales ingresos que obtiene de sus exportaciones de hidrocarburos deben permitir a Ashjabat adquisiciones de nuevo material, como los diez carros de combate T-90 que están pendientes de recepcionar. Éstos se unirán a una sustancial flota de 670 unidades de T-72 en un estado de alistamiento difícil de determinar debido a la ya mencionada opacidad que el sistema político del país impone a la prensa nacional e internacional.

La Fuerza Aérea turkmena dispone de dos escuadrones de dotados de 11 MiG-29 cada uno y de dos biplazas para las funciones de entrenamiento y formación de sus pilotos. Se encuentran posicionados en la Base Aérea de Mary-2. En su inventario cuentan también 3 Sukhoi Su-7B y 65 Su-17 aunque son aviones que hace ya décadas que están obsoletos y su capacidad operativa sería extremadamente limitada ${ }^{53}$. Nunca fueron puestos en servicio después de ser heredados de la Unión Soviética y es muy poco probable que exista una posibilidad real de llegar a utilizarlos. El apoyo cercano debería correr a cargo del Sukhoi Su25. De las 43 unidades de que disponen, todas menos dos se encuentran en proceso de remodelación. Eso dejaría prácticamente como único modelo operativo a los dos Albatros, Aero L-39, cuya función sería, fundamentalmente, de entrenamiento.

\begin{tabular}{llll}
\hline Tipo de aeronave & Modelo & Número & Observaciones \\
\hline Caza & MiG-29/MiG-29UB & 22 & \\
\hline Caza-bombardero & Su-7B & 3 & \\
\hline Caza-bombardero & Su-17 & 65 & 41 en retrofit \\
\hline Bombardero táctico & Su-25MK & 2 & \\
\hline Transporte ligero & An-26 & 1 & \\
\hline Entrenamiento & L-39 & 2 & \\
\hline Helicóptero ataque & Mi-24 & 10 & \\
\hline Hel. Transporte medio & Mi-8 & 8 & \\
\hline
\end{tabular}

Aeronaves de las Fuerzas Aéreas de Turkmenistán. Fuente: Elaboración propia a partir de la base de datos de Jane's Defence.

\footnotetext{
53 El Su-7B dejó de fabricarse en 1972 y el Su-17 en 1990, aunque se mantiene en servicio de forma oficial en media docena de países.
} 
En esta ocasión, tampoco el ala rotatoria parece ser una prioridad para el Gobierno de Ashjabat. La Fuerzas Aérea sólo cuenta con 10 unidades de helicópteros de ataque Mi-24 y 8 de transportes del tipo Mi-8. El bagaje es, claramente, insuficiente y se puede considerar la Fuerza Aérea turkmena como prácticamente inexistente a todos los efectos.

Turkmenistán dedica por encima de los 250 millones de dólares anuales a sus gastos de defensa.

\section{6. Consecuencias}

La composición de las Fuerzas Armadas de un país dice mucho de las intenciones de sus gobernantes, de cuáles son sus prioridades y cuáles sus amenazas percibidas. Los países objeto de estudio tienen muchos condicionantes adicionales en la composición de las mismas; el carácter que tienen de "restos de serie" heredados de la disolución de la Unión Soviética no es el menor de ellos. Sin embargo, a veinte años de sus declaraciones de independencia, se perciben muy pocos esfuerzos por mantener actualizados los inventarios de material y la formación del personal. Más significativo todavía es el hecho de que no se han adoptado medidas tendentes a la modificación de las obsoletas estructuras y organizaciones ex soviéticas.

Las conclusiones lógicas que pueden extraerse son:

- Las amenazas percibidas por parte de los países de Asia Central no tienen un carácter de enemigo convencional externo. Las identidades estatales no son fuertes y sigue existiendo un sentimiento de pertenencia a grupos de menor entidad o a entidades supranacionales. No tiene, por consiguiente, mucho sentido, enfatizar la modernización de unas Fuerzas Armadas cuya principal misión debería ser la de garantizar la independencia respecto de enemigos externos. Por otro lado, la localización geopolítica de las repúblicas centroasiáticas, rodeadas de grandes potencias regionales muchas veces superiores a ellas, desincentiva la inversión en un instrumento que, por poderoso que pudiera llegar a ser, no iba a cambiar el equilibrio regional ni disuadir a uno de los grandes actores en sus empeños.

- Se tiene muy en cuenta el problema de los extremismos y del terrorismo y, por otro, pero de forma asociada muchas veces, el del narcotráfico. Sin embargo, los beneficios que obtienen algunas élites de los tráficos ilícitos pueden prevenir su erradicación. La amenaza terrorista se percibe con más fuerza en las grandes potencias que en las repúblicas centroasiáticas, a pesar de observar los efectos que han tenido en otros países. En cualquier caso, la entidad, calidad y medios disponibles de sus fuerzas, y la extensión y complejidad orográfica de casi todo el territorio convierten la tarea en un esfuerzo titánico caso de querer acometerse.

- La disposición, encuadramiento disperso y equipamiento de los ejércitos, así como su notable falta de apoyos aéreos, los equipara en cierta medida con otras unidades paramilitares y diluye la posibilidad de utilización de las Fuerzas Armadas como instrumento político por un posible rival al poder. Puede deducirse que, como es frecuente en regímenes con democracias poco desarrolladas - es mayor la preocupación por una posible utilización no deseada de los militares en contra del poder que el deseo de disponer de un instrumento al servicio del Estado.

- El control, normalmente presidencial, la disposición geográfica de las fuerzas - al menos de las más significativas - y su, en muchos casos, nula capacidad de proyección o de enfrentamiento con otra fuerza regular indica en algunos países la intención de utilizar el instrumento militar más en el interior del país y en labores de 
seguridad interior que para las funciones primarias de defensa y apoyo a la política exterior.

- La influencia de potencias extranjeras en las repúblicas centroasiáticas es muy importante. Tanto las alianzas en que están incluidas la mayor parte de las repúblicas como las potencias regionales y globales pretenden mantener un control sobre la región o, al menos, evitar que ninguna otra lo ostente.

\section{Conclusiones}

La repentina disolución de la Unión Soviética permitió a algunos de los pueblos que la integraban - especialmente los bálticos - alcanzar la soñada independencia y acercarse a Europa. Con mayores o menores dificultades, estos países intentaron volver a recuperar su identidad anterior al dominio de Moscú. Para otros, sin embargo - y más allá de las consideraciones nacionalistas - la aparición de fronteras nacionales donde antes había sólo demarcaciones regionales supuso un verdadero problema organizativo. No es de extrañar que algunas de las repúblicas centroasiáticas fueran de las más reticentes al divorcio de Rusia.

El final de la convivencia dentro de las mismas fronteras fue un duro reto para la economía y las relaciones comerciales de estos países. Para sus Fuerzas Armadas, basadas muchas veces en cuadros de mando rusos, y desplegadas en función de las necesidades del conjunto de la Unión y no de los intereses, riesgos y amenazas nacionales de cada república, la situación fue igualmente negativa.

No es de extrañar, en este contexto, que la Comunidad de Estados Independientes resultara atractiva para muchas de ellas en un principio. Mientras se respetaba la capacidad de cada cual para decidir, se aprovechaba el paraguas ruso para todo lo demás. Los difíciles años de la transición en que Boris Yeltsin ocupaba el Kremlin no fueron, no obstante, los más propicios para consolidar la alianza. La acelerada evolución del panorama geopolítico de los últimos años ha supuesto un reto al que tampoco se ha sabido hacer frente de la forma más adecuada y eficiente. Los intereses industriales y la agresividad mostrada por gobiernos posteriores terminaron de disgregar al grupo. Nuevas iniciativas han surgido, desde entonces, para intentar llenar el hueco que deja una CEI inoperante.

La Organización del Tratado de Seguridad Colectiva pretendió recoger el testigo en lo relacionado con los aspectos defensivos pero los esporádicos enfrentamientos de Moscú con otras repúblicas y la injerencia de terceras potencias - sobre todo a raíz de las operaciones en Afganistán después de los atentados de Al Qaeda el 11 de septiembre de 2001 en Estados Unidos - no permitieron un desarrollo todo lo profundo que muchos hubieran querido.

Muy distinto es el caso de la Organización para la Cooperación de Shanghái. Incluso descontado el distinto ritmo a que se mueven los acontecimientos en Occidente y en Oriente, la OCS ha conseguido definir fronteras concretas donde antes había focos de tensión y ha sentado de forma regular en la mesa a rusos y chinos con las cuatro repúblicas centroasiáticas que no se acogen a su estatus de neutralidad ante Naciones Unidas (caso de Turkmenistán). El interés de potencias como India, Irán y Pakistán por formar parte de la Organización - y el de otras potencias por evitarlo - es buena muestra del potencial que tiene este mecanismo generador de confianza y dialogo en Asia en todos los órdenes. 
Si para rusos y chinos la OCS es una fuente de ventajas considerable, para las repúblicas centroasiáticas lo es aún en mayor medida. Para los países productores de hidrocarburos, la posibilidad de diversificar su mercado y vías de distribución les concede una gran ventaja industrial y les libera de la tiranía del sistema de conducción diseñado por Moscú. La certeza de estar amparados por una de las grandes potencias regionales en equilibrio con la otra supone un incentivo nada desdeñable a la hora de hacer negocios.

Esta situación geográfica - rodeadas de grandes potencias que se equilibran - está detrás del poco relevante papel que juegan las Fuerzas Armadas en unos países que siguen utilizando, en buena medida, los medios y organizaciones que han sobrevivido al paso de dos décadas desde la disolución de la URSS. Aparte de pequeñas escaramuzas y de alguna participación en misiones internacionales, el uso que se ha dado a los ejércitos centroasiáticos ha estado más centrado en la seguridad interior que en la exterior. Ejemplos deplorables de la inadecuación de los medios y los procedimientos a esa misión se siguen produciendo hasta nuestros días.

Los recursos naturales y una política de apertura han permitido a Kazajstán convertirse en la referencia de la política regional por encima de un Uzbekistán que, tradicionalmente, asumía ese papel. Para los kazajos, igual que para los turkmenos, el interés se está desplazando hacia la zona productora del Caspio. La pugna por la distribución de los hidrocarburos de la región ocupará la mayor parte del tiempo y los recursos de estos gobiernos en los próximos años junto con problemas de seguridad interior.

Estos problemas vendrán - están viniendo, he hecho - de la mano del narcotráfico, que utiliza a estos países como lugar de tránsito y mercados secundarios, y de la difusión del radicalismo islamista con peligrosas ramificaciones hacia la provincia china de Xinjiang. La mayor contribución que las repúblicas centroasiáticas pueden hacer a la seguridad regional y a la global es el combate contra estos dos enemigos. Tanto la OTSC como la SCO han puesto en marcha organismos para hacer frente a lo que los chinos dieron en llamar los tres males: el separatismo, el extremismo y el terrorismo en esta zona.

Estas dos organizaciones pueden ser clave a la hora de mediar en las disputas que, irremediablemente, surgirán entre las repúblicas más occidentales y las orientales en torno a la utilización del agua. La gestación de proyectos conjuntos de distribución de energía ${ }^{54}$ y el desarrollo armónico de todos los países es la única vía para un avance pacífico.

La situación en la que quede Afganistán después de la prevista retirada de las fuerzas de combate occidentales en 2014 no dejará, sin duda, de tener un impacto en la seguridad de la región entera. Un país inestable o con una gobernanza ineficiente no sólo supondrá un riesgo de contagio hacia sus vecinos del norte sino que puede llegar a convertirse en un campo de batalla de luchas por la dominación regional entre potencias asiáticas y en una permanente espada de Damocles sobre el inestable equilibrio en que ya se mueve la zona.

Pasarán muchos años antes de que las Fuerzas Armadas de las cinco repúblicas estén en condiciones de jugar un papel constructivo en la región. Hasta entonces será importante evitar que su papel sea negativo para la convivencia regional y para la interna de cada país.

\footnotetext{
${ }^{54}$ Como el proyecto CASA-1000 (Central Asia - South Asia) de distribución de electricidad.
} 